\title{
Vinculando ciencia y política pública La Ley de Aguas Nacionales desde las perspectivas sistémica y de servicios ecosistémicos
}

\author{
Linking Science and Public Policy: The National Waters Law under the Perspectives of Systems \\ Thinking and Ecosystem Services
}

\author{
Yair Asael Alpuche Álvarez, Luzma Fabiola Nava, \\ Maritza Alejandra Carpio Candelero y Diana Isabel Contreras Chablé*
}

Resumen: A partir de un modelo teórico integrado por los enfoques en sistemas socioecológicos y servicios ecosistémicos discutimos las relaciones entre ciencia y política pública en México. Por medio del estudio del principal instrumento de gestión de recursos en agua en México, la Ley de Aguas Nacionales, subrayamos los progresivos esfuerzos realizados para integrar una gama del conocimiento científico a los procesos de elaboración de políticas públicas. Sin embargo, tanto la elaboración de políticas públicas como la generación de marcos normativos no siempre evolucionan al mismo ritmo que la ciencia, y viceversa. El reto consiste en cómo las instituciones y autoridades gubernamentales se adaptan al mismo tiempo que la producción de conocimientos científicos avanza. El diseño y la formulación de política públicas necesitan adaptarse en tándem con la ciencia misma.

Palabras clave: política pública, recursos hídricos, pensamiento sistémico, sociohidrología, socioecosistemas.

*Yair Asael Alpuche Álvarez es candidato a doctor en Geografía. Departamento de Geociencias y Manejo de Recursos Naturales, Facultad de Ciencias. Universidad de Copenhague. Øster Voldgade 10, $1350 \mathrm{Kbh}$ K, Área VI, Edificio: 06-2-605. Tel: +4535 3270 35. Correo-e: yaa@ign.ku.dk. orCID: https://orcid. org/0000-0002-0412-0953. Luzma Fabiola Nava (autora para correspondencia) es catedrática Conacyt en el Centro del Cambio Global y la Sustentabilidad, A.C., calle Centenario Instituto Juárez s.n., colonia Reforma, 86080, Villahermosa, Tabasco, México. Tel: +52(993) 315 0612\#120. Correo-e: Inava@conacyt.mx. orcid: https://orcid.org/0000-0003-4047-6006. De igual manera es investigadora invitada en el International Institute for Applied Systems Analysis (IIASA). Schlossplatz 1 - A-2361, Laxenburg, Austria. nava@iiasa.ac.at. Maritza Alejandra Carpio Candelero es asistente de investigación en el Proyecto Fordecyt 273646, liderado por el Centro del Cambio Global y la Sustentabilidad, A.C., calle Centenario Instituto Juárez s.n., colonia Reforma, 86080. Villahermosa, Tabasco, México. Tel: +52(993) 315 0612\#120. Correo-e: maralecarcan.11@gmail.com. ORCID: https://orcid.org/0000-0002-9569-7802. Diana Isabel Contreras Chablé, asistente de investigación en el Proyecto fORDEсут 273646 liderado por el Centro del Cambio Global y la Sustentabilidad, A.C., calle Centenario Instituto Juárez s.n., colonia Reforma, 86080, Villahermosa, Tabasco, México. Tel: +52(993) 315 0612\#120. Correo-e: dianaicc96@gmail.com. orcid: https://orcid.org/00000002-8934-0081.

Artículo recibido el 1 de diciembre de 2019 y aceptado para su publicación el 1 de diciembre de 2020.

DOI: http://dx.doi.org/10.29265/gypp.v30i2.881 
Abstract: From a theoretical model integrated by the socioecological systems and ecosystem services approaches, we discuss the relations between science and public policy in Mexico. Through the study of Mexico's main water resource management instrument, the National Waters Law, we underline the progressive efforts made to integrate a range of scientific knowledge into public policy-making processes. However, both public policy-making and the generation of regulatory frameworks do not always evolve at the same rate as science, and vice versa. The challenge is how institutions and governmental authorities adapt at the same time as the production of scientific knowledge progresses. Public policy design and formulation need to be adapted in tandem with science itself.

Keywords: public policy, water resources, systems thinking, sociohydrology, socioecosystems.

\section{INTRODUCCIÓN}

T a creación de conocimientos científicos y estrategias metodológicas para la gestión y la preservación de los recursos naturales ha avanzado en las últimas décadas (Galán et al., 2012: 5; Rodríguez Romero y Cubillos González, 2012: 80). Se espera que el conocimiento científico trascienda la esfera social, económica, política y ambiental de la vida pública. De manera que el capital humano, generador de conocimientos científicos, establezca los puentes necesarios para vincular la práctica científica con el quehacer político y la elaboración de políticas públicas basadas en resultados provenientes de las ciencias naturales, las ciencias sociales y las ciencias en ingenierías (Pohl, 2008: 46). Sin embargo, la transferencia de conocimiento, entre la academia y la política pública, es un fenómeno ocasional, limitado y poco reconocido, pero sumamente necesario para responder a los problemas socioambientales y robustecer los procesos de diseño, implementación y evaluación de políticas públicas (Alfaro y Martín, 2015: 1348; Juntti et al., 2009: 207-208; Lemos y Morehouse, 2005: 57-59; Stubrin y Kababe, 2014: 73-75).

En la actualidad, el paradigma de la sustentabilidad es el más importante para el desarrollo y la construcción de políticas públicas e instrumentos de gestión. Promueve una visión integral de tres esferas estrechamente ligadas: la social, la económica y la ambiental (Leff, 1994: 2-3; Ramírez Treviño et al., 2003: 55-57). Sin embargo, es el conocimiento científico el que define las formas en las cuales estas grandes esferas del desarrollo interactúan entre sí. En la esfera social, los conocimientos científicos favorecen el entendimiento colectivo de los procesos complejos que ocurren en torno a la vida humana y potencializan la participación de los actores sociales en la cocreación de conocimientos y la ejecución de acciones positivas en torno a un problema común (Capel, 2014: 14-16; Senabre et al., 2018: 36-37; Reed, 2008: 2426-2427). En la esfera económica, los conocimien- 
tos científicos favorecen los flujos de inversión para la innovación y la transferencia de tecnología y la promoción de un mercado impulsado por la competencia y la complementariedad de saberes científicos (Bullen et al., 2004: 7-8; Jones, 2011: 116-118). Por último, la producción de conocimientos científicos también promete el establecimiento de esquemas de gobernanza ambiental para conservar la biodiversidad y fomentar el desarrollo socioeconómico sustentable (Brenner y Vargas del Río, 2010: 116-199; López de Lara et al., 2018: 71-72).

La generación de conocimientos sobre temas específicos respectivos a cada una de las esferas del desarrollo requiere de mecanismos y marcos conceptuales que permitan integrar la información científica transdisiciplinaria (Pohl, 2008: 47-48). Recientemente uno de los enfoques con mayor aceptación es el paradigma de los sistemas socioecológicos (SSE). Dicho paradigma deriva de la teoría de sistemas y de las ciencias de la complejidad; en su conjunto, ambos marcos disciplinarios están basados respectivamente en el incremento de los conocimientos sobre la impredecibilidad de la naturaleza y la sociedad y en las nociones propuestas por la teoría general de sistemas propuesta por von Bertalanffy en 1968; así como en la no linealidad, la incertidumbre, las propiedades emergentes, la escala y la autoorganización (Berkes et al., 2002: 5-8). Construcciones teóricas a las cuales se suman los aportes de Gunderson y Holling (2002 citado en Berkes et al., 2002: 6) sobre la adaptación y resiliencia de los sistemas, el entendimiento de la construcción de sistemas entremezclados humano-naturaleza. Otro de los aportes más importantes al entendimiento de estos sistemas es el marco propuesto por Elinor Ostrom (2009: 419-422) sobre la forma en que los recursos naturales son utilizados, gestionados y organizados.

El enfoque de los SSE representa uno de los más relevantes de los últimos tiempos para la gestión de las relaciones sociedad-naturaleza (Schlüter et al., 2019: 1) al involucrar una visión holística del funcionamiento de la realidad. Dentro de los tópicos que se estudian bajo esta propuesta, se encuentra la disponibilidad de recursos como incentivo del comportamiento social y los modos de relacionarse con los recursos naturales, así como los efectos consecuentes en la dinámica del mismo (Castillo y Velázquez, 2015: 19). La relativa flexibilidad de las ideas propuestas por el marco de los SSE permite su adaptación a campos específicos de la investigación.

Esto puede observarse en la propuesta de los sistemas sociohidrológicos (sSH) de Sivapalan et al. (2012). La sociohidrología consiste en una perspectiva sistémica con énfasis en la gestión de los recursos hídricos la cual propone que los seres humanos son también parte del ciclo hidrológico y que esta integración es 
DIAGRAMA 1. Aproximación teórica del objeto de estudio

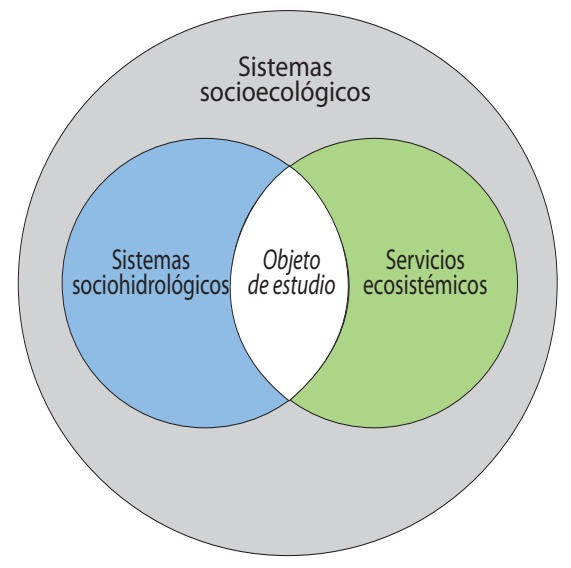

Fuente: Elaboración propia.

necesaria para poder hacer predicciones más adecuadas respecto a la dinámica de los procesos hidrológicos. Esta perspectiva considera al agua y a la sociedad como dos sistemas que han coevolucionado (Sivapalan et al., 2012: 1271). Con la vinculación del marco conceptual de sSE a las políticas públicas, se puede contribuir al entendimiento de los problemas y ubicar los puntos críticos, dentro de una enmarañada red de procesos complejos, que deberán ser solventados para fomentar relaciones recíprocas que se traduzcan en beneficios compartidos entre el conjunto de dinámicas sociales y procesos encaminados al equilibrio ecológico (Schlüter et al., 2019: 1-3). Debido al reciente progreso del campo de los SsH, nosotros utilizaremos el concepto considerándolo un subcomponente de los SSE con todas las implicaciones teóricas implicadas. En el diagrama 1 se muestra nuestra aproximación teórica.

Otro concepto ampliamente utilizado, no solo en el estudio de los SSE sino en la construcción de políticas públicas, es el paradigma de servicios ecosistémicos (SE) (Wong et al., 2014: 1). Se consideran SE, todos aquellos beneficios que el ser humano aprovecha de los ecosistemas. El paradigma de SE permite comprender los beneficios que la sociedad recibe y percibe del medio natural o de los ecosistemas (MEA, 2005: 49-63). Al respecto, existe una gran cantidad de esfuerzos realizados para evaluar la provisión de los SE desde múltiples perspectivas y mediante la utilización de metodologías variadas (Martín-López et al., 2014: 220). 
Por su relevancia en la construcción de políticas públicas, la inclusión de los marcos de SSH y de SE es un factor interés de investigación, sobre todo para comprender la adaptación y la potencial adaptación de los instrumentos de gestión vigentes. Con base en el estudio de la Ley de Aguas Nacionales (LAN) de México nos preguntamos: ¿Cuenta la LAN con una perspectiva sistémica y de servicios ecosistémicos? De ser así, ¿¿de qué manera han sido integrados estos marcos dentro de la LAN? Para responder a estas preguntas proponemos analizar la LAN a partir de un modelo teórico integrado por los enfoques en SSH y SE. Buscamos identificar y discutir las relaciones entre ciencia y política existentes dentro del principal instrumento de gestión de recursos en agua en México. Argumentamos que la LAN, vigente desde 1992, refleja los esfuerzos realizados para integrar los procesos de generación del conocimiento científico y la elaboración de políticas públicas. El artículo se organiza de la siguiente manera. La segunda sección presenta los métodos y el caso de estudio de la LAN y el enfoque sistémico. La tercera sección enuncia los resultados obtenidos. En la cuarta sección se discuten los resultados según el modelo teórico integrado por los enfoques en SSH y SE. La última sección ofrece las conclusiones

\section{MÉTODOS}

Seleccionamos un instrumento normativo relacionado con la gestión del agua, al ser un recurso de interés de investigación de los autores. Con base en esto escogimos la LAN tomando en consideración el alcance federal de la ley y la derivación de un marco de gestión de recursos hídricos aplicable a la escala nacional.

\section{La Ley de Aguas Nacionales}

México es un mosaico sociohidrológico y sociopolítico. Sus principales características son la riqueza de recursos hídricos y ecosistemas acuáticos (Ávila García, 2008: 48-53; Arreguín Cortés et al., 2004: 251; Martínez Austria et al., 2019: 178; Martínez Austria, 2013: 166; Martínez Austria y Patińo-Gómez, 2012: 13; Nava, 2006: 1-2), la heterogeneidad de su distribución espacial y temporal (Arreguín Cortés et al., 2011: 21-24; Arreguín Cortés et al., 2010: 53-58; Martínez Austria, 2013: 169-172), y las visiones vehiculadas por las distintas políticas del agua, así como los diversos modelos y programas de desarrollo económico (Aboites Aguilar et al., 2010: 22-29; Aboites Aguilar, 2009: 99-100; Dourojeanni et al., 2002: 5). En su conjunto, estos matices han incidido en la gestación del México de hoy, un país que se ha esforzado por la modernidad de la gestión de recursos hídricos, para lo cual se ha zambullido en la ola de principios relacio- 
nados con los derechos humanos, el cuidado del medio ambiente y la sustentabilidad. Sin embargo, esta realidad no ha sido inmediata; es el resultado de una consecución de enfoques que han impregnado la génesis de la normatividad que rige la gestión del agua.

Dentro del México contemporáneo, la gestión del agua de la nación está enmarcada por la Constitución Política de los Estados Unidos Mexicanos (CPEUM) y dos leyes federales (Aboites Aguilar et al., 2010: 27-28; Aboites Aguilar, 2005: 25-31). La LAN, en conjunto con la Ley Federal de Derechos (LFD), regula las respectivas disposiciones constitucionales y establece los principios y mecanismos para la gestión de recursos hídricos en el país (oCDE, 2013: 44). La CPEum señala al gobierno federal como propietario de todas las fuentes de agua (art. 27); reconoce el Derecho Humano al Agua y al Saneamiento (DHAS) y al Medio Ambiente Sano (DHMAs) en materia de agua (art. 4), y confiere a los gobiernos locales la responsabilidad de proveer servicios de agua y saneamiento (art. 115). En consecuencia, la LAN establece que las aguas nacionales deben ser administradas por el Poder Ejecutivo Federal (art. 4); descentraliza la gestión de los recursos hídricos a la escala de cuenca (art. 5); define a la Comisión Nacional del Agua (Conagua) como la institución central del agua (art. 9), y fomenta la participación de usuarios, sociedad civil y sector privado en los procesos de gestión del recurso (capítulo V, título VIII de la CPEUM; OCDE, 2013: 100).

La LAN es el motor normativo de la política del agua en México. Resultado de una consecución de medidas tomadas en torno al agua durante el siglo xx, la génesis de la LAN ha transitado de la centralización hacia la planeación, la descentralización y la regionalización (Aboites Aguilar et al., 2010: 21; 31-37; Domínguez, 2019: 41-48; Nava: 2018: 28-30; OCDE, 2013: 39-47;). Promulgada en 1992, la LAN ha sido reformada 288 ocasiones por medio de ocho decretos presidenciales; tan solo en 2004 la LAN fue reformada 233 ocasiones. ${ }^{1}$ En la LAN del 29 de abril de 2004, un total de 114 artículos fueron reformados, 66 adicionados y dos derogados (Ortiz Rendón, 2005: 13). Desde entonces, el propósito ha consistido en crear mayores espacios de diálogo entre la sociedad y el gobierno; fortalecer el empoderamiento de los usuarios locales, la democracia participativa y el establecimiento de compromisos de la sociedad, y moder-

\footnotetext{
${ }^{1}$ Las fechas de los decretos oficiales de la federación (DOF) son: el 15-02-1993 (4 veces); 29-04-2004 (223 veces); 18-04-2008 (1 vez); 20-06-2011 (10 veces); 08-06-2012 (30 veces); 07-06-2013 (4 veces); 11 08-2014 (3 veces); 24-03-2016 (13 veces).
} 
nizar la visión de la relación Estado vis-à-vis la política hídrica (Beutelspacher et al., 2010: 394-395).

La LAN ha regido la política nacional del agua y ha contribuido a la gestión integrada de recursos hídricos (GIRH) por cuenca hidrológica (Aboites Aguilar et al., 2010: 37; Arreguín Cortés et al., 2011:31-33; Cotler, 2015: 32-33; Domínguez, 2019: 97-99; Nava, 2018: 28-30; ocde, 2013: 44; 153; 179). Siendo los retos en la materia aún impresionantes (Arreguín Cortés et al., 2010: 74; Domínguez, 2019: 40; López Morales, 2017: 39-40; Nava, 2018: 38-40), la LAN ha favorecido un decálogo de cambios: 1) impulsar el proceso de descentralización de la gestión del agua; 2) garantizar la sustentabilidad financiera de la gestión del agua; 3) transferir las responsabilidades de los recursos hídricos a los organismos, consejos y órganos auxiliares de cuencas, e incentivar e institucionalizar la participación local; 4) redefinir el marco regulatorio de los recursos hídricos y los servicios de agua en términos de gestión, coordinación, cooperación, financiamiento y control; 5) consolidar el papel de la Conagua como la autoridad encargada de todos los asuntos relacionados con el agua; 6) establecer mercados de agua y los correspondientes precios del agua; 7) eliminar algunos subsidios en áreas seleccionadas; 8) transferir la gestión de distritos de riego a las asociaciones de usuarios del agua; 9) fortalecer la gestión municipal y estatal del agua y servicios de saneamiento en zonas urbanas; 10) posibilitar la participación del sector privado en la gestión de servicios de agua mediante concesiones (Domínguez, 2019: 74-77; Domínguez, 2011: 6; Ortiz Rendón, 1993; Wilder, 2010: 4-8; OCDE, 2013: 45; 51; 110; 150).

En consecuencia, el agua ha dejado de ser considerada un insumo. Hoy en día, es un bien finito, vulnerable, con valor simbólico, económico y ambiental. La conservación y la preservación del agua, tanto en términos cuantitativos como cualitativos, son criterios que el enfoque actual de gestión del agua considera y a los cuales se suma el importante reconocimiento de la persona como actor necesario para la gestión del recurso y la procuración del bienestar individual y social (Âvila García, 2006: 234-236; 240-246; Domínguez, 2019: 34; Gutiérrez Rivas, 2008: 85-87; Mussetta, 2009: 72-77; Romero Pérez, 2007: 120-125; 133-139).

El estudio de la gestión del agua requiere una aproximación que permita sistematizar los elementos involucrados desde la generación de los servicios hasta el uso y la descarga del recurso natural. Como se ha indicado, los paradigmas de SSH y SE son marcos de conocimiento científico que al incorporarse al lenguaje político ayudarían a los tomadores de decisiones a reconocer los elementos fun- 
damentales del manejo apropiado de las dimensiones social, ecológica, económica y política referentes al agua.

\section{Enfoque sistémico}

Partimos de la premisa que la LAN procura la integración de las fuentes del recurso hídrico y la sociedad a través de un conjunto de normas que rigen las interacciones entre los distintos elementos involucrados. Por lo tanto, presumimos que la LAN anuncia un sistema sociohidrológico. Con una visión de simplificar las complejidades del ssH que presenta la gestión del recurso hídrico en cualquier territorio, se utilizó como base el documento de Wiek y Larson (2012), el cual descompone el complejo en un sistema de entradas y salidas con una relativa sencillez que facilita la identificación de los elementos nucleares de un sistema, además de incentivar la integración de los actores sociales. En el cuadro 1 se observan los elementos utilizados para la evaluación del enfoque sistémico aplicados a la LAN. Para esto, se seleccionaron y adaptaron tres de los componentes de la metodología de propuesta: fundamentos del sistema, elementos del sistema y estructura del sistema social.

Utilizamos el método mixto a partir de la interpretación cualitativa del contenido de la LAN para posteriormente cuantificar las frecuencias de elementos clave con el objetivo de explorar el grado de representación de cada elemento o concepto en la ley. Considerando la propuesta metodológica de Wiek y Larson, y derivado de las características de los componentes mencionados en esta actividad, diseñamos estrategias similares para cuatro secciones: fundamentos del sistema, elementos del sistema, estructura del sistema social y, con fines exploratorios, aportaciones del marco de SE. Las particularidades de cada sección se mencionan a continuación:

1. Para la sección de fundamentos del sistema, realizamos una revisión en extenso de la LAN para identificar palabras clave (PC) que se asocian a los conceptos mencionados en el marco de sistemas de Wiek y Larson (2012). En esta sección no se requirió una aproximación cuantitativa debido a que se priorizó la identificación de los argumentos asociados a la visión y los principios que rigen la LAN. No obstante, se hicieron algunas búsquedas de información textual para la formalización de algunos argumentos, como el asociado al concepto de sustentabilidad.

2. En cuanto a la sección de elementos del sistema, revisamos el contenido de la LAN para identificar las palabras clave (PC). Posteriormente, utilizamos el 
CUADRO 1. Caracterización del enfoque sistémico

\begin{tabular}{lll}
\hline \multicolumn{1}{c}{ Concepto } & \multicolumn{1}{c}{ Descripción } \\
\hline 1.0 & \multicolumn{1}{c}{$\begin{array}{c}\text { Fundamentos del sistema } \\
\text { 1.1 }\end{array}$} & $\begin{array}{l}\text { Perspectiva sistémica } \\
\text { Perspectiva que vincula aspectos ecológicos, sociales, económicos, } \\
\text { técnicos, legales a múltiples escalas del sistema de agua. }\end{array}$ \\
1.2 & Enfoque en actores sociales & $\begin{array}{l}\text { Quién hace qué y por qué con el agua, quién causa o contribuye con } \\
\text { los problemas y quién tiene la voluntad o el deber de hacer algo para } \\
\text { resolverlos. }\end{array}$ \\
$1.3 \quad \begin{array}{l}\text { Discurso transparente sobre } \\
\text { metas yalores } \\
\text { Perspectiva comprensiva } \\
\text { sobre sustentabilidad del } \\
\text { agua }\end{array}$ & $\begin{array}{l}\text { Especificar, revelar y negociar las necesidades, preferencias y visiones } \\
\text { entre actores sociales junto con las implicaciones a los sistemas de agua. } \\
\text { Incluir la riqueza de la sustentabilidad, la integridad socioecológica, } \\
\text { la suficiencia de los medios de vida, la justicia social, la equidad } \\
\text { intergeneracional. Evitar soluciones a problemas aislados e inequitativos. }\end{array}$
\end{tabular}

Elementos del sistema

2.1 Forma de delimitación regional

2.1.1 Concepto de delimitación La manera en que se determina el área geográfica de interés.

2.2 Dominios de actividad

2.2.1 Suministros

Relacionado con la proveniencia del agua; cómo se adquiere, se accede o se gestiona:

2.2.2 Distribuidores

Actividades por las cuales se distribuye el agua a los usuarios por medio de sistemas naturales o de ingeniería para facilitar el uso y consumo.

2.2.3 Usos

Relacionado con la manera en que las personas usan, consumen y conservan el agua para varios propósitos incluyendo deseos y necesidades económicas, humanas y ecológicas.

2.2.4 Salidas

Incorpora las actividades de tratamiento de agua después de que estas fueron usadas, incluyendo cómo se utilizan y manejan las aguas residuales y los efluentes para moverse a través del sistema.

2.2.5 Transversales

Actividades que influyen en uno o varios de los dominios anteriores: planeación, regulación, estudio, monitoreo, etc.

\section{Estructura del sistema social}

2.3.1 Incorporación de actores, intenciones y reglas

Se reconocen para cada actividad, los actores sociales, sus competencias y valores, y los modos de interacción.

Fuente: Elaboración propia con base en Wiek y Larson (2012). 
programa Nvivo 12 Plus para realizar la búsqueda de texto y el cálculo de la frecuencia de las PC, misma que fue asistida con el programa Adobe Reader como fuente de corroboración de la información. Además, este último programa facilitó la búsqueda de la ubicación de las PC en el texto.

3. En cuanto a la estructura del sistema social, identificamos los actores sociales, las instituciones y los tomadores de decisiones (AIT). En segundo lugar, cuantificamos las frecuencias de aparición de cada uno de los AIT y se definieron las relaciones entre ellos, las reglas e intenciones. Con base en los resultados se construyó una red de actores utilizando el programa $\mathrm{R}$ 4.0.2.

4. Para explorar la inclusión del marco de los $S E$, en el análisis de contenido, hicimos una búsqueda de los artículos de la ley que involucran la intervención de la LAN en el manejo de uno o más SE. Como guía sobre los SE, utilizamos las publicaciones de la Evaluación de los Ecosistemas del Milenio (MEA, 2005) y la Clasificación Internacional Común de Servicios Ecosistémicos (CICES, por sus siglas en inglés) (Cices basado en la MEA). Anotamos los artículos y fragmentos donde se hizo mención de los mismos. También realizamos un análisis del discurso de la ley para identificar la mención indirecta de los SE. Esto con el fin de explorar la existencia de estos servicios en el parafraseo de la ley.

\section{RESULTADOS}

Esta sección está organizada según las cuatro secciones mencionadas previamente.

\section{Fundamentos del sistema}

En general, la LAN se centra en el manejo y la regulación del acceso al agua. La nube de palabras (figura 1), acerca del contenido de la ley, no refleja los componentes sociales y ecológicos del funcionamiento del sistema sociohidrológico. Más bien, en primera instancia se observan las escalas de gestión de agua, desde el concepto geográfico de cuenca y la organización político-administrativa, la cual considera la representatividad de la ley a la escala nacional. Lo que se presenta a continuación consiste en un esfuerzo de profundizar en la abstracción del sistema sociohidrológico planteado en la LAN para analizar el grado de integración de conceptos tan comúnmente utilizados en el lenguaje del manejo de recursos naturales.

\section{Perspectiva sistémica de la LAN}

A partir de los fundamentos del ssH, el principal concepto utilizado en la LAN 
FIGURA 1. Nube de palabras del contenido de la LAN

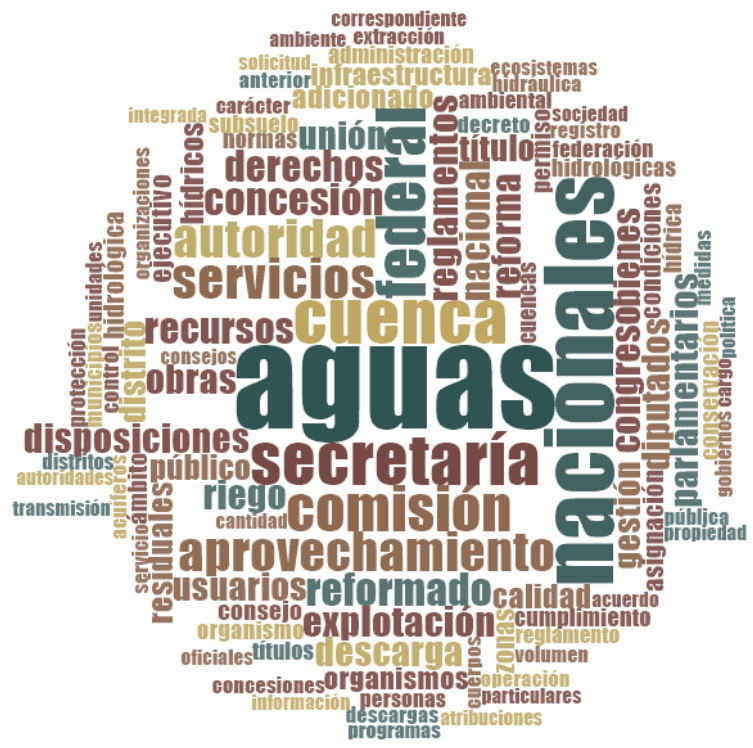

Fuente: Elaboración propia con base en la LAN.

que se refiere a una perspectiva sistémica es el de gestión integrada de los recursos hídricos (GIRH). Dicho concepto se describe en el artículo (art.) 3 de la ley, y se define como: "Proceso que promueve la gestión y desarrollo coordinado del agua, la tierra, los recursos relacionados con estos y el ambiente, con el fin de maximizar el bienestar social y económico equitativamente sin comprometer la sustentabilidad de los ecosistemas vitales. Dicha gestión está íntimamente vinculada con el desarrollo sustentable". Para la aplicación de esta ley en relación con este concepto se consideran primordialmente agua y bosque. El concepto aparece en 25 ocasiones, repartido en 16 artículos. El esquema 1 muestra el árbol de palabras para este concepto. Se puede observar un uso generalizado y amplio del concepto, vale la pena destacar que se utiliza como un objetivo a alcanzar mediante la ejecución de la presente ley. Este argumento se sustenta por la anteposición, al concepto principal, de los verbos contribuir, alcanzar, lograr y avanzar. 


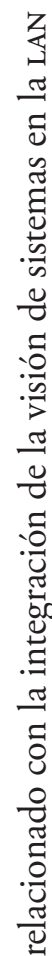
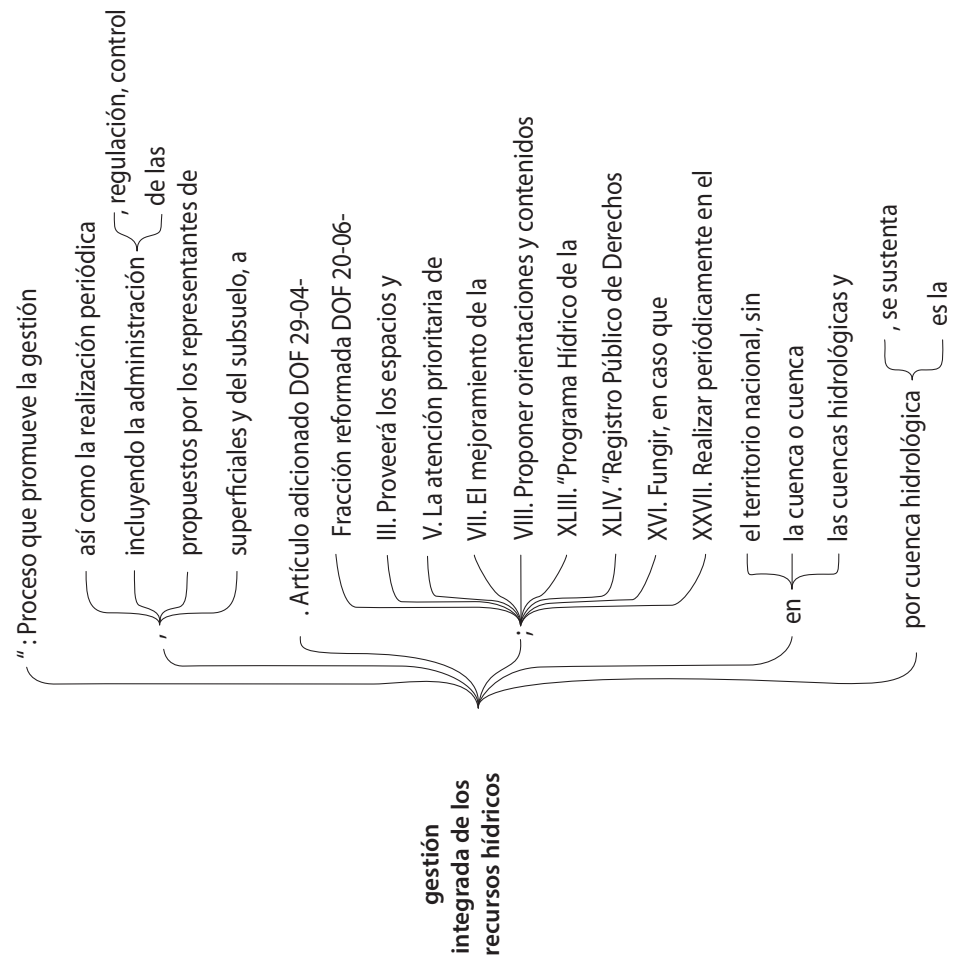

要

กี

อัด

$\frac{\pi}{2}$

$\frac{\text { 苟 }}{\frac{0}{2}}$

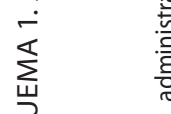

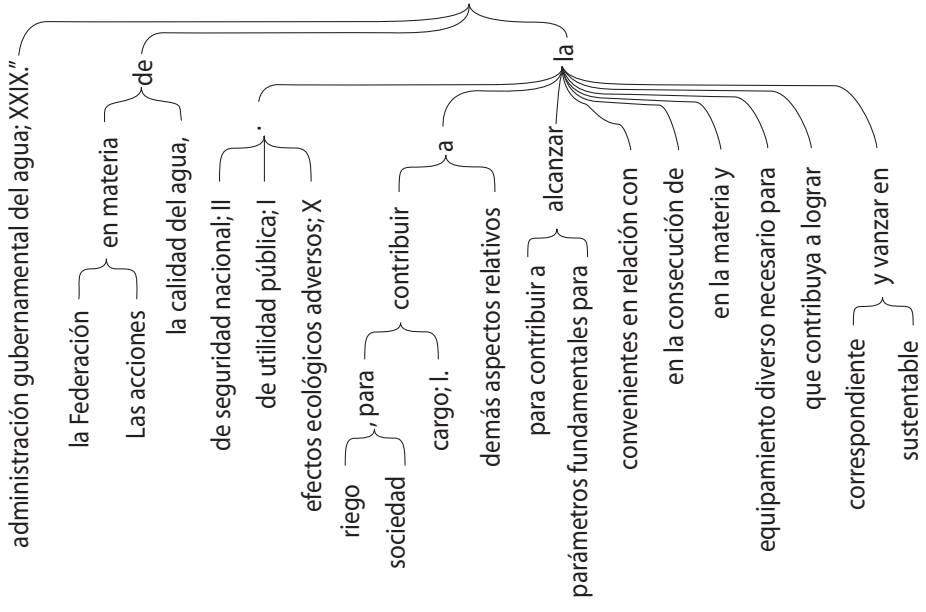

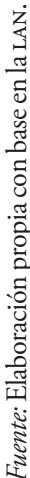




\section{Enfoque de actores sociales}

En esta sección, la palabra clave utilizada fue "actores"; sin embargo, esta palabra únicamente aparece en una ocasión en el artículo 14 Bis 5 de la siguiente manera: "La gestión de los recursos hídricos se llevará a cabo en forma descentralizada e integrada privilegiando la acción directa y las decisiones por parte de los actores locales y por cuenca hidrológica”. No obstante, mediante la revisión del contenido se puede distinguir una construcción de una estructura sociopolítica en el que actores locales, instituciones y tomadores de decisiones desempeñan roles de importancia en la gestión del sistema sociohidrológico. Por ejemplo, en el artículo 5 se plasman las atribuciones del nivel superior de gobierno (Ejecutivo Federal) en relación con los otros niveles (estatal y municipal) y la institución, en este caso la Conagua, que debe fungir como medio de comunicación y centro de toma de decisiones en materia de la gestión del agua.

\section{Discurso transparente sobre metas y valores}

El caso del discurso transparente sobre metas y valores es similar al anterior. No se identificaron palabras clave para este fundamento, sin embargo, la LAN en su artículo 14 Bis 5 hace referencia a 22 principios sobre las metas y valores. En el Anexo 1, se enlistan los principios mencionados. Además, la ley utiliza estos principios para guiar la integralidad del resto de los artículos. Esto se supone a partir de la siguiente expresión encontrada como anotación al final del artículo mencionado: "Los principios de política hídrica nacional establecidos en el presente Artículo son fundamentales en la aplicación e interpretación de las disposiciones contenidas en esta Ley y en sus reglamentos, y guiarán los contenidos de la programación nacional hídrica y por región hidrológica y cuenca hidrológica”.

\section{Perspectiva comprensiva sobre sustentabilidad del agua}

En cuanto a la perspectiva comprensiva sobre sustentabilidad del agua, la LAN cuenta con una definición para el desarrollo sustentable: "Proceso evaluable mediante criterios e indicadores de carácter hídrico, económico, social y ambiental, que tiende a mejorar la calidad de vida y la productividad de las personas, que se fundamenta en las medidas necesarias para la preservación del equilibrio hidrológico, el aprovechamiento y la protección de los recursos hídricos, de manera que no se comprometa la satisfacción de las necesidades de agua de las generaciones futuras". Además, se utilizaron las palabras clave sustentable y sustentabilidad para ampliar el contexto de uso del concepto. Este fue encontrado en nueve artículos de la ley y en el apartado de transitorios. El esquema 2 muestra los árboles de 


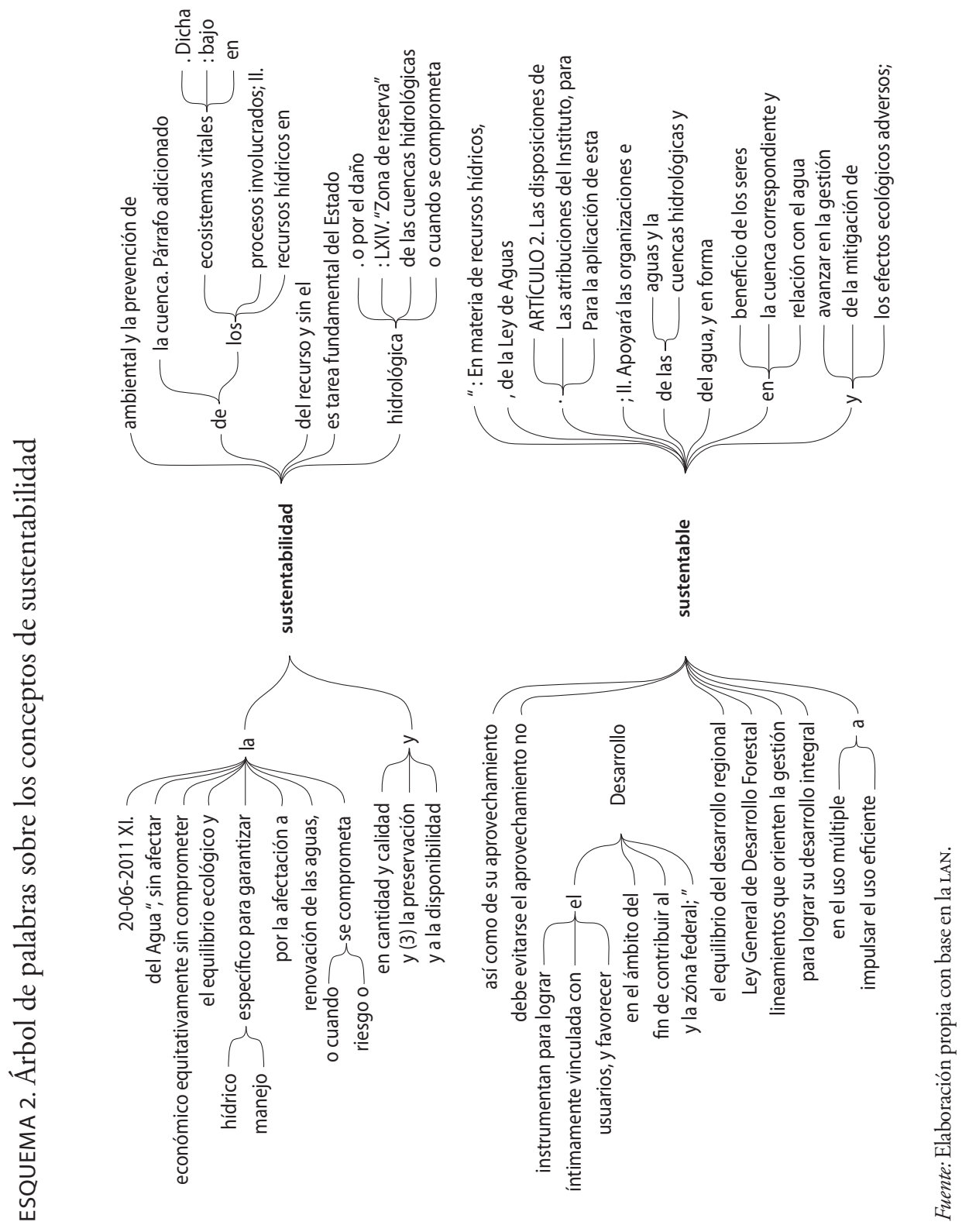


palabras para ambos conceptos. En este caso, ambos conceptos se presentan como un objetivo, pero también forman parte de las características del manejo de recursos. De esta forma se especifica la búsqueda de una continuidad integral de los valores económicos, ambientales y sociales asociados al agua y las cuencas.

\section{Elementos del sistema}

Como parte de los elementos del sistema, Wiek y Larson (2012) establecen la forma de delimitación regional como la unidad de análisis o el sistema socioecológico bajo gestión.

\section{Forma de delimitación regional (concepto de delimitación)}

En nuestro caso identificamos un concepto central, el de cuenca. Este aparece en la ley un total de 316 ocasiones en 64 artículos. Sin embargo, otros conceptos identificados como unidades de delimitación derivados de la noción central de cuenca son: cuenca hidrológica, región hidrológica y región hidrológico-administrativa. En el anexo 3 se enlistan las frecuencias correspondientes y la ubicación de las palabras clave en el contenido de la LAN. Por su parte, en la gráfica 1 ejemplificamos la proporción de uso de cada una de estas PC.

Uno de los elementos señalados para la inclusión del enfoque sistémico que realmente están representados en la LAN, corresponde al de la delimitación de las

GRÁFICA 1. Forma de delimitación regional (porcentaje)

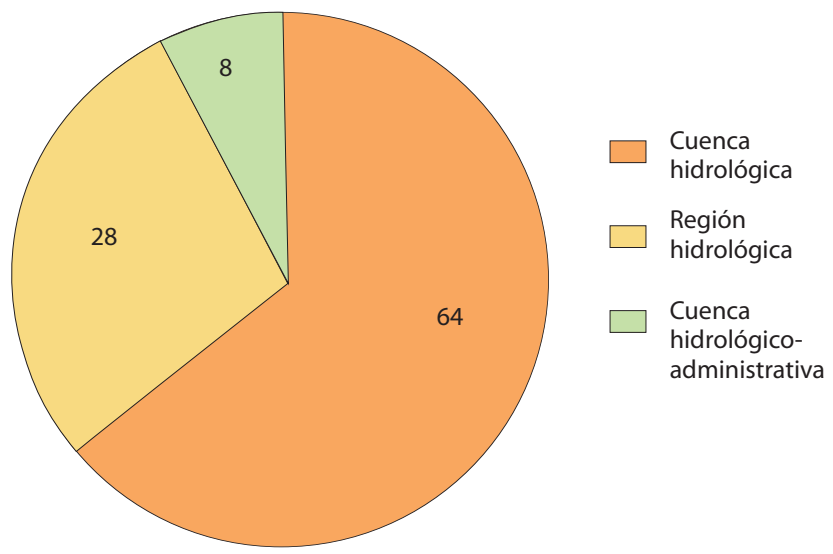

Fuente: Elaboración propia con base en la LAN. 
unidades de gestión mediante cuencas. La cuenca es la unidad mínima de gestión, $y$, tal como lo señala la literatura, es la unidad que muestra la integralidad de los flujos de agua (por ejemplo en Dourojeanni et al., 2002).

\section{Dominios de actividad}

Por sí misma, la LAN no reconoce a los ecosistemas suministradores del agua como un recurso o un servicio. Sin embargo, como lo muestra el diagrama 2, en la ley se describen algunos ecosistemas relacionados con el agua como ríos, esteros, humedales, lagos y lagunas. En lo referente a los distribuidores, el sistema de agua potable y alcantarillado fue considerado como el único concepto relacionado con esta categoría. Este sistema solo se menciona en una ocasión dentro de la ley, por lo que su funcionamiento y sus interacciones con los suministradores y usos no se describe suficientemente. No obstante, sí se reconocen los actores involucrados en su supervisión, tales como los gobiernos estatales y municipales. En cuanto a los usos, la LAN cuenta con un título dedicado a los tipos de uso que la mencionada ley regula. De manera cuantitativa, es el uso doméstico el que está mejor representado en la LAN (35\%). Este se define en el artículo $3^{\circ}$ como el referente

DIAGRAMA 2. Componentes del sistema sociohidrológico representados en la LAN

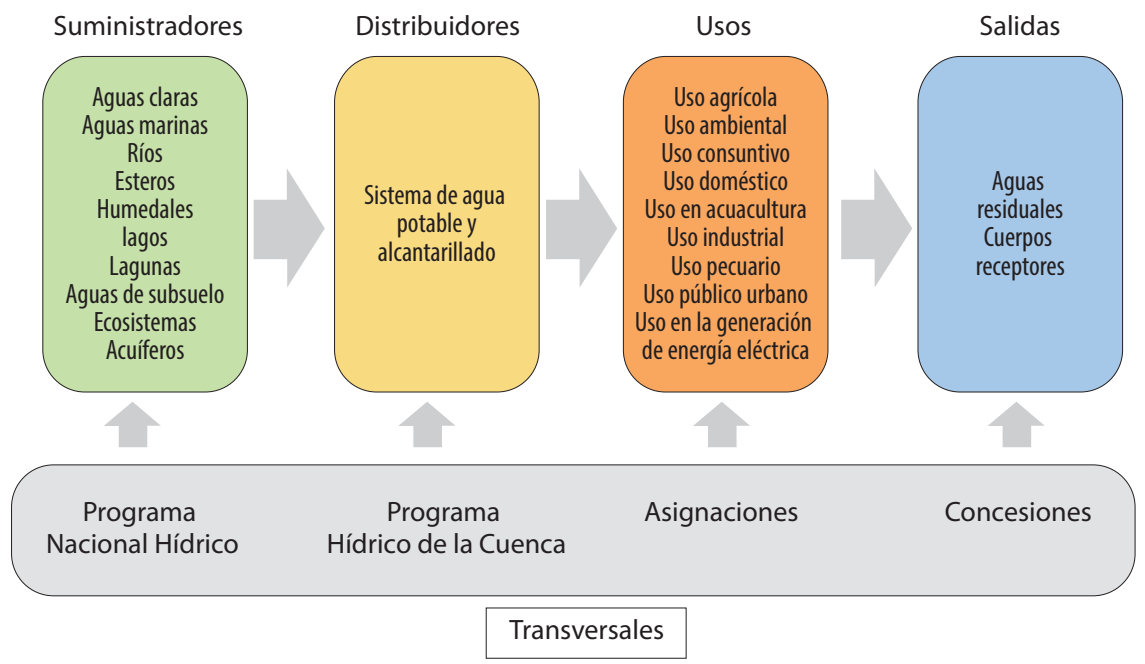

Fuente: Elaboración propia con base en Wiek y Larson (2012). 
al aprovechamiento del agua en "hogar, riego de sus jardines y de árboles de ornato, incluyendo el abrevadero de animales domésticos que no constituya una actividad lucrativa [...]”.

La LAN no plantea una visión centrada en el ecosistema. La LAN identifica los cinco elementos del sistema presentado por Wiek y Larson (2012): suministradores, distribuidores, usuarios, salidas y transversales. Esto quiere decir que, al menos parcialmente, la LAN establece principios de pensamiento sistémico. El sistema mejor representado en la ley es el sistema de suministro de agua.

Existen elementos fuente (suministradores) descritos como ecosistemas acuáticos que aunque son bienes nacionales, pueden concesionarse o asignarse a un particular. Esta agua se utiliza de diferentes formas mediante un sistema de agua potable y alcantarillado encargado de distribuir el agua a los usuarios. El producto de los usos del recurso son las salidas o aguas residuales y todos interactúan mediante instrumentos que regulan la intensidad del uso del agua, de las características del sistema de distribución y los parámetros fisicoquímicos de las aguas. No obstante, Wiek y Larson (2012) no incluyen en este modelo la diversidad de usuarios, por ejemplo, no todos los usuarios del uso agrícola producen las mismas salidas, ya que estas dependen de las prácticas agrícolas. Por lo tanto, el modelo aquí provisto no demuestra una complejidad; al contrario, es lineal pero de gran utilidad para identificar los componentes fundamentales del sistema de distribución. Al respecto, la gráfica 2 muestra diez conceptos asociados al dominio de los suministros o suministradores. Los acuíferos destacan con un 35 por ciento del total de presencia de los tipos de suministradores.

Sin embargo, tal y como lo muestra la gráfica 3, dentro de los dominios de actividad asociados a los usos, el doméstico $(35 \%)$ es el que refleja mayor frecuencia en la LAN, seguido del uso público urbano (19\%) y el uso agrícola (14\%). En caso contrario los usos industrial, pecuario y en acuacultura están presentes en menor proporción, con 3 por ciento cada uno.

\section{ESTRUCTURA DEL SISTEMA SOCIAL}

La incorporación de actores, intenciones y reglas, con base en la clasificación realizada, refleja un total de 23 instituciones (figura 2). La Conagua y el Consejo Técnico son, en términos de redes, los actores con mayor grado. Al explorar la centralidad de la red, la Conagua, según la proximidad y cercanía con otros nodos (instituciones), es la institución con mayor desempeño en los ámbitos de la intermediación; rol correspondiente a su función como institución central que conecta a otros actores. Otros actores creados específicamente para la gestión 
GRÁFICA 2. Conceptos asociados a los suministros (porcentaje)

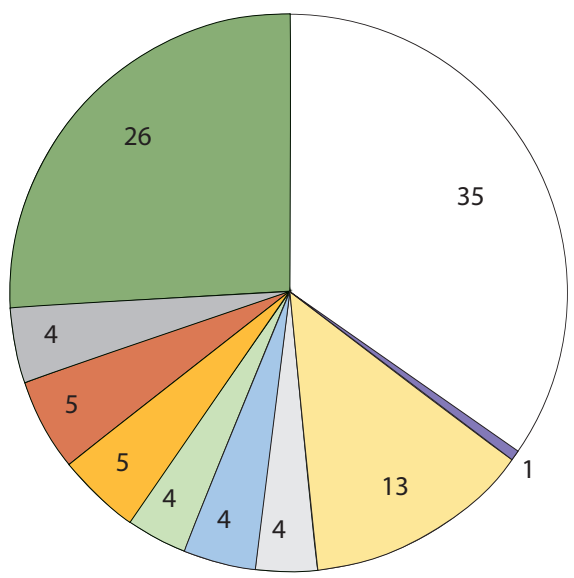

$\square$ Acuíferos

$\square$ Aguas claras

$\square$ Aguas de subsuelo

$\square$ Aguas marinas

$\square$ Esteros

$\square$ Ríos

$\square$ Lagos

$\square$ Lagunas

Humedales

$\square$ Ecosistemas

Fuente: Elaboración propia con base en la LAN.

GRÁFICA 3. Conceptos asociados a los usos (porcentaje)

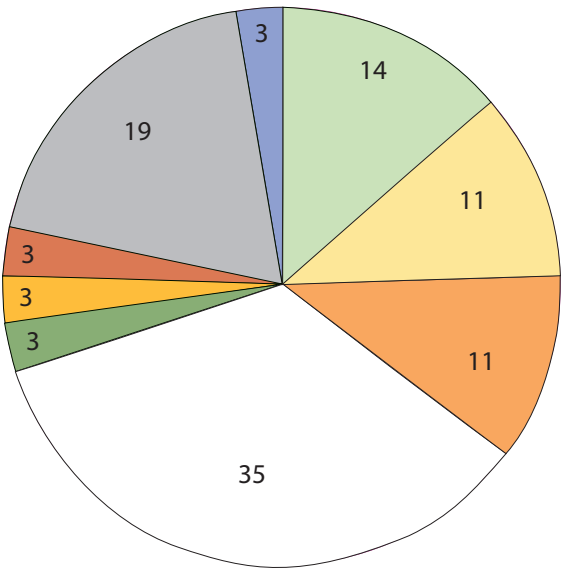

Uso agrícola

Uso ambiental

Uso consuntivo

Uso doméstico

Uso en acuacultura

Uso industrial

Uso pecuario

Uso público urbano

Uso en la generación de energía eléctrica

Fuente: Elaboración propia con base en la LAN. 
FIGURA 2. Red de instituciones presentes en la LAN

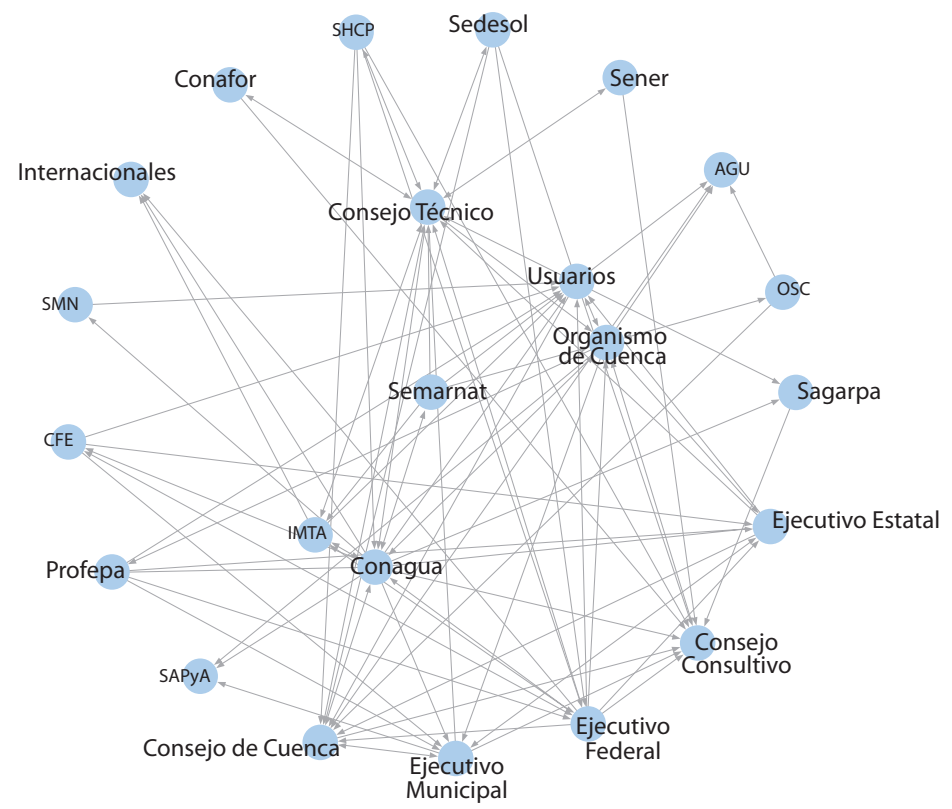

Fuente: Elaboración propia con base en la LAN. Leyenda: Semarnat (Secretaría de Medio Ambiente y Recursos Naturales), Conafor (Comisión Nacional Forestal), sHCP (Secretaría de Hacienda y Crédito Público), Conagua (Comisión Nacional del Agua), Sedesol (Secretaría de Desarrollo Social), Sener (Secretaría de Energía), Sagarpa (Secretaría de Agricultura, Ganadería, Desarrollo Rural, Pesca y Alimentación), IMTA (Instituto Mexicano de Tecnología del Agua), sapya (Sistema de Agua Potable y Alcantarillado), osc (Organizaciones de la Sociedad Civil), Profepa (Procuraduría Federal de Protección al Ambiente), CFE (Comisión Federal de Electricidad), sMN (Servicio Meteorológico Nacional), AGU (Asamblea General de Usuarios).

de los recursos hídricos como los organismos de cuenca y los distintos consejos también muestran una centralidad importante, lo que refleja su relevancia en la síntesis de la información entre la red de actores. Los usuarios también tienen una alta centralidad. Sin embargo, cabe mencionar que este grupo es muy diverso ya que, como se mencionó, en los dominios de actividad existen nueve tipos de uso. Con respecto a las reglas que rigen cada una de las instituciones, en el título segundo de la ley se establecen las principales atribuciones de cada una de las siguientes instituciones: Ejecutivo Federal (art. 6), Semarnat (art. 8), Conagua (principalmente art. 9), Consejo Técnico (10 a 11), organismos de cuenca (12 Bis a 12 Bis 6), consejos de cuenca (13 a 13 Bis 4), AGU (13 Bis 1), 
osc y usuarios (14, 14 Bis), Consejo Consultivo (14 Bis 1), IMTA (14 Bis 2) y Profepa (14 Bis 3).

Los principales actores son la Conagua, el Ejecutivo Federal, los gobiernos estatales y municipales, el Consejo Consultivo y el Organismo de Cuenca. Todos estos intervienen en la toma de decisiones, soportada por la información que obtienen de "instituciones secundarias" que no necesariamente son inferiores en jerarquía a la Conagua, pero que cumplen el papel de soporte con la información que generan, por ejemplo, la Comisión Nacional Forestal (Conafor) y el Instituto Mexicano de Tecnología del Agua (IMTA). Los usuarios y la sociedad civil se relegan a tener representantes en los consejos de cuenca. En estos, junto con la participación de los representantes de los gobiernos y de la Conagua, se generan propuestas de gestión a la escala de cuenca. Esta situación genera una arquitectura de gobernanza que refleja cierto policentrismo, pero donde el poder se distribuye heterogéneamente entre los actores. Aunado a esto, el papel de la Conagua aparece con tanta importancia que potencialmente aparece como un actor absoluto en la gestión del agua, el cual vehicula la priorización de los intereses gubernamentales en la gestión de los recursos hídricos.

\section{INCLUSIÓN DEL MARCO DE SERVICIOS ECOSISTÉMICOS}

En la LAN, la noción de SE está presente únicamente como una categoría general de los beneficios de la naturaleza. Los avances sobre servicios ecosistémicos han demostrado la importancia de tener una perspectiva integradora cuando se valoran los servicios ecosistémicos (Martín-López et al., 2014). Además, debido a la complejidad de los procesos socioecológicos que producen los servicios ecosistémicos, existen fuertes relaciones de interdependencia entre múltiples servicios ecosistémicos y los ecosistemas que los proveen. En la LAN, aunque la ley inscribe diez servicios ambientales, que corresponden a tres SE descritos en el marco de la Evaluación de los Ecosistemas del Milenio, el principal servicio regulado (no puntualmente descrito como un SE) es el aprovisionamiento de agua, de lo cual deducimos que alimentos y energía lo son también (véase el cuadro 2).

El resto de los servicios mencionados representa servicios de regulación que prestan otros ecosistemas. Aunque se presume la necesidad de conservar múltiples servicios ecosistémicos, estos se conservan mediante la gestión adecuada de los ecosistemas que los proveen y no únicamente mediante el cuidado de la cantidad y calidad del agua. Con el supuesto de poder encontrar servicios implícitos en el texto, se encontraron algunas menciones no reconocidas como servicios ecosistémicos, pero que conceptualmente y a través de interpretación reconocen la 
CUADRO 2. Presencia y ausencia de servicios ecosistémicos considerados en la MEA (2005) dentro de la LAN

\begin{tabular}{|c|c|c|c|c|}
\hline & $\begin{array}{l}\text { Servicio } \\
\text { ecosistémico }\end{array}$ & $(x)$ & Ubicación & Fragmento \\
\hline \multirow[t]{6}{*}{ Provisión } & Alimentos & 0 & Artículo 3 & $\begin{array}{l}\text { La aplicación de agua nacional para el riego destinado a la } \\
\text { producción agrícola. }\end{array}$ \\
\hline & Agua & $(2)$ & $\begin{array}{l}\text { Contenido } \\
\text { de la LAN }\end{array}$ & El servicio se menciona de manera difusa en todo el texto. \\
\hline & Energía & $(2)$ & $\begin{array}{l}\text { Artículos } \\
2,7,41 \\
\text { y } 80\end{array}$ & $\begin{array}{l}\text { El aprovechamiento de aguas nacionales para generar } \\
\text { energía eléctrica destinada a servicios públicos; Generación } \\
\text { de energía eléctrica para servicio público; Las personas físicas } \\
\text { o morales deberán solicitar concesión a "la Comisión" cuando } \\
\text { requieran de la explotación, uso o aprovechamiento de aguas } \\
\text { nacionales con el objeto de generar energía eléctrica, en los } \\
\text { términos de la ley aplicable en la materia). }\end{array}$ \\
\hline & $\begin{array}{l}\text { Fibrasy } \\
\text { materiales }\end{array}$ & ( $)$ & $\begin{array}{l}\text { Artículos } \\
3 \text { y } 176\end{array}$ & $\begin{array}{l}\text { Materiales pétreos: Materiales tales como arena, grava, } \\
\text { piedra y/o cualquier otro tipo de material utilizado en la } \\
\text { construcción, que sea extraído de un vaso, cauce o de } \\
\text { cualesquiera otros bienes señalados en el artículo } 113 \text { de } \\
\text { esta Ley; los concesionarios para la extracción de materiales } \\
\text { pétreos deberán recuperar los bancos de acuerdo con las } \\
\text { condiciones ambientales y de paisaje de la zona donde } \\
\text { se localicen, para lo cual deberán devolver al sitio los } \\
\text { materiales resultado del despalme y, en su caso, el producto } \\
\text { de excavaciones, mediante nivelaciones o cortes que } \\
\text { faciliten la revegetación, de acuerdo con las normas que al } \\
\text { efecto emita"La Comisión"). }\end{array}$ \\
\hline & Bioquímicos & & N/A & N/A \\
\hline & $\begin{array}{l}\text { Recursos } \\
\text { genéticos }\end{array}$ & $x$ & N/A & $\mathrm{N} / \mathrm{A}$ \\
\hline \multirow[t]{3}{*}{ Regulación } & $\begin{array}{l}\text { Regulación } \\
\text { del clima }\end{array}$ & ( & Artículo 3 & "Regulación climática”, "Captura de carbono” \\
\hline & $\begin{array}{l}\text { Regulación } \\
\text { de las } \\
\text { enfermedades }\end{array}$ & $\mathrm{N} / \mathrm{A}$ & N/A & N/A \\
\hline & $\begin{array}{l}\text { Regulación } \\
\text { del agua }\end{array}$ & ( & $\begin{array}{l}\text { Artículos } \\
3,9 \text { y } 78\end{array}$ & $\begin{array}{l}\text { "Conservación de los ciclos hidrológicos","Control de } \\
\text { las inundaciones","mantenimiento de escurrimiento", } \\
\text { Promover en el ámbito nacional el uso eficiente del agua y } \\
\text { su conservación en todas las fases del ciclo hidrológico [... ]; } \\
\text { garantizar los flujos mínimos que requiera la estabilidad } \\
\text { de los cauces, lagos y lagunas, y el mantenimiento de las } \\
\text { especies acuáticas. }\end{array}$ \\
\hline
\end{tabular}


CUADRO 2. Presencia y ausencia de servicios ecosistémicos considerados en la MEA (2005) dentro de la LAN (continuación)

\begin{tabular}{|c|c|c|c|c|}
\hline & $\begin{array}{l}\text { Servicio } \\
\text { ecosistémico }\end{array}$ & & Ubicación & Fragmento \\
\hline & $\begin{array}{l}\text { Purificación } \\
\text { del agua }\end{array}$ & ( & Artículo 3 & Purificación de los cuerpos de agua \\
\hline & Polinización & N/A & N/A & N/A \\
\hline \multirow[t]{7}{*}{ Culturales } & $\begin{array}{l}\text { Religiosidad- } \\
\text { Espiritualidad }\end{array}$ & $\mathrm{N} / \mathrm{A}$ & N/A & N/A \\
\hline & $\begin{array}{l}\text { Ecoturismoy } \\
\text { recreación }\end{array}$ & N/A & N/A & N/A \\
\hline & Estético & N/A & N/A & N/A \\
\hline & Inspiracional & N/A & N/A & N/A \\
\hline & Educación & & $\begin{array}{c}\text { Artículos } \\
9 \text { y } 12 \\
\text { Bis } 6\end{array}$ & $\begin{array}{l}\text { Mejorar y difundir permanentemente en el ámbito nacional } \\
\text { el conocimiento sobre la ocurrencia del agua en el ciclo } \\
\text { hidrológico, la oferta y demanda de agua, los inventarios } \\
\text { de agua, suelo, usos y usuarios y de información pertinente } \\
\text { vinculada con el agua y su gestión, con el apoyo que } \\
\text { considere necesario, por parte de otras instancias del orden } \\
\text { federal, de gobiernos estatales y municipales, así como de } \\
\text { usuarios del agua, de organizaciones de la sociedad y de } \\
\text { particulares. }\end{array}$ \\
\hline & $\begin{array}{l}\text { Sentido de } \\
\text { lugar }\end{array}$ & N/A & $\mathrm{N} / \mathrm{A}$ & $\mathrm{N} / \mathrm{A}$ \\
\hline & $\begin{array}{l}\text { Herencia } \\
\text { cultural }\end{array}$ & N/A & N/A & $\mathrm{N} / \mathrm{A}$ \\
\hline \multirow[t]{3}{*}{ Soporte } & $\begin{array}{l}\text { Formación } \\
\text { de suelo }\end{array}$ & $(2)$ & Artículo 3 & "Formación de suelo" \\
\hline & $\begin{array}{l}\text { Ciclado de } \\
\text { nutrientes }\end{array}$ & N/A & N/A & N/A \\
\hline & $\begin{array}{l}\text { Producción } \\
\text { primaria }\end{array}$ & N/A & N/A & N/A \\
\hline
\end{tabular}

Fuente: Elaboración propia con base en la LAN. 
importancia de los ecosistemas acuáticos, por ejemplo el caso de los recursos pétreos correspondientes a los materiales de construcción. Pese a que se pueden encontrar algunos servicios implícitos y se han mencionado otros servicios directamente en el texto, la diversidad de servicios que se conjugan con el agua es menor a la que la literatura reconoce (véase MEA, 2005; Haines-Young y Potschin, 2017). Además, solo se reconocen los servicios de regulación, desconociendo la pluralidad de valores socioculturales y económicos que los ecosistemas asociados al agua pueden proveer. Con base en la presente investigación, podemos decir que el concepto de SE no tiene mayor relevancia en el cuerpo del documento, ni en ninguno de los procesos de gestión, sanción o planeación.

\section{DISCUSIÓN}

El modelo teórico integrado por los enfoques en SSH y SE revela cierto grado de ambivalencia. Pese a que la LAN no ha sido necesariamente concebida como un instrumento sistémico de reglamentación de la gestión de los recursos hídricos en México, presenta rasgos asociados al paradigma de la GIRH. Al respecto, cabe mencionar que la palabra sistema aparece en 32 ocasiones en la LAN haciendo referencia al conjunto de mecanismos relacionados con la obtención de información y el proceso de toma de decisiones. Además, la LAN refleja tres dimensiones importantes incluidas en la gestión del recurso: social, económica y ambiental. Aunque estas dimensiones son interdependientes, presentan características únicas que las diferencian en sus elementos y procesos conectores.

La dimensión social tiene una alta complejidad, pues además de incluir el conjunto de necesidades fisiológicas y de infraestructura, integra diversos factores subjetivos como los valores relacionales que se atribuyen al agua y a los ecosistemas asociados. La complejidad social involucrada en la gestión del agua y, por consiguiente, en la sustentabilidad, es reducida a una participación ciudadana esporádica cuando se realizan las reuniones de consejos de cuenca. Sin embargo, los representantes sociales corresponden a categorías preestablecidas según las formas de uso clasificadas en la ley; la cual no considera la diversidad cultural de los usuarios, ni los contextos múltiples a los que se enfrentan. En este sentido, la dimensión social en la ley, ubica en un nivel menor a la sociedad dentro del proceso de toma de decisiones; consecuentemente, los valores socioculturales de agua y los ecosistemas se vuelven una herramienta difusa en dicho proceso.

La dimensión económica tiene una gran cantidad de componentes de regulación de uso y aprovechamiento del agua. El agua tiene un alto valor para el desarrollo local, regional y federal. Al ser un recurso escaso y necesario para 
producir múltiples bienes y servicios, promueve una competencia de mercado que lo convierte en un medio de crecimiento económico a la vista de los tomadores de decisiones. El gobierno utiliza herramientas de concesión y asignación para facilitar que determinados grupos usen el agua para la generación de bienes y servicios comerciables que se traduzcan en ingresos económicos y contribuyan a la economía en diferentes escalas. Desde un enfoque sistémico también se puede dibujar una dinámica económica entre la autoridad, los usuarios, las cuotas, los pagos, etc. Las sanciones y regulaciones por la contaminación del agua reflejan un mecanismo económico diseñado para subsanar los daños en el subsistema ambiental. Sin embargo, en términos normativos, las relaciones transversales entre la LAN y los instrumentos destinados a la reglamentación y gestión de la dimensión económica-ambiental del agua son difusas y complejas.

Por último, la dimensión ambiental es la que menos representación tiene como sistema. Dos de los componentes más importantes de la dinámica ecológica del ciclo del agua son los ecosistemas acuáticos y la vegetación. La literatura respectiva reconoce la importancia de conservar la vegetación ribereña para mitigar los impactos de la contaminación difusa por residuos de nutrientes utilizados en la agricultura (Ouyang et al., 2010; Zhao et al., 2019). La evapotranspiración es dependiente de la vegetación y en su ausencia la precipitación disminuye. México se enfrenta a un gran problema de deforestación, que consecuentemente afectaría el funcionamiento del ciclo hidrológico (Salinas-Castillo y Treviño-Garza, 2002: 59-75). Sin embargo, la LAN, siendo la ley del agua no establece una conexión con los ecosistemas forestales.

No obstante, la forma de interacción entre las tres dimensiones dentro de la LAN, o subsistemas, se debe principalmente a los componentes transversales. Según Weik y Larson (2012: 3158), estos inciden en diferentes partes del sistema de gestión del agua. Por lo tanto, el enfoque sistémico es una herramienta útil para organizar y adaptar la gestión del agua en México.

\section{CONCLUSIONES}

La ciencia no siempre evoluciona al mismo ritmo que la elaboración de políticas públicas y la generación de marcos normativos, y viceversa. La LAN fue creada más de una década antes de que el MEA se publicara en 2005; por lo que podemos inferir que la LAN ha sido, sobre todo, el resultado de procesos y de problemas puntuales que han emergido de manera progresiva. En 1988 se promulgó la Ley General de Equilibrio Ecológico y Protección Ambiental (LgeEpa), y cuatro años más tarde se decretó la LAN; todo esto dentro de la administración federal de 
Carlos Salinas de Gortari (1988-1994), época que corresponde también a la entrada en vigor del Tratado de Libre Comercio de América del Norte (TLCAN), mejor conocido hoy como el Tratado entre México, Estados Unidos y Canadá (T-Mec), el cual incluye un acuerdo específico para tratar asuntos ambientales en América del Norte. Sin embargo, no podemos negar que la creación de la LAN en 1992 no se haya beneficiado de una dosis de conocimientos creados por los científicos en México o en el mundo.

De manera progresiva, la LAN ha evolucionado conforme a los avances en materia de agua a nivel mundial. Analizarla desde la perspectiva del modelo teórico integrado por los enfoques en SSH y SE permite deducir que la LAN refleja una visión de sistemas sociohidrológicos y de servicios ecosistémicos. La incorporación reciente del DHAS y del DHMAs en materia de agua indican, además de una tendencia a nivel mundial vehiculada por Naciones Unidas (UN), la Organización Mundial de la Salud (wHO, 2005) y otras instituciones afines, que los hacedores de política pública en México han empezado a interesarse en los conocimientos disciplinarios con el fin de tomar decisiones robustas e integradas.

Las reformas constantes a la LAN, tomadas con una visión de sistemas, favorecen acuerdos y crean sinergias. La teoría de sistemas, y otras herramientas de simulación, son herramientas accesibles a los tomadores de decisiones para hacer tangibles los cambios de paradigma de la gestión de los recursos hídricos en México. La obtención de beneficios sociales, económicos y ambientales para todos los usuarios, incluido el medio ambiente como sumistrador, depende entonces de gestionar el agua como un recurso holístico en donde sean consideradas todas y cada una de las múltiples interacciones establecidas en torno al agua. Hacer que la política pública y los marcos normativos específicos sean ad hoc y prospectivos es un objetivo fundamental de los gobiernos que valorizan y consideran los avances científicos, el crecimiento económico, la salud y la longevidad; la reducción de la pobreza; así como la adaptación y mitigación al cambio climático.

Los esfuerzos para vincular la ciencia y las políticas están cambiando de diferentes formas. Los foros de consulta sobre la creación de una nueva LAN y las consultas para la elaboración del Plan Hídrico Nacional llevados a cabo durante 2019, así como la formulación de los Planes Hídricos Regionales en curso, muestran las intenciones del gobierno actual y de la actual administración de la Conagua de adaptar y modernizar la política del agua en México y favorecer la gestión del recurso con base en una visión sistémica del funcionamiento ecológico, sociocultural, económico y político del agua. En todos los casos, el reto consiste en cómo las instituciones y las autoridades gubernamentales pueden adaptarse a medida que la 
creación de conocimientos científicos evoluciona. No obstante, no olvidemos que la política pública puede desalinearse con la ciencia misma, a menos que la formulación de política pública evolucione en tándem. Gڤิ

\section{REFERENCIAS}

Aboites Aguilar, L. (2005), "Del agua nacional al agua mercantil ambiental: Algunas ideas para hacer una investigación sobre historia contemporánea de los usos del agua en México", en J.M. Durán, M. Sánchez y A. Escobar Ohmstede (eds.), El agua en la historia de México, Zamora, Mich., Universidad de Guadalajara-Cucsh/El Colegio de Michoacán, pp. 25-31.

Aboites Aguilar, L. (2009), La decadencia del agua de la nación: Estudio sobre desigualdad social y cambio politico en México, segunda mitad del siglo XX, Ciudad de México, El Colegio de México, 145 pp.

Aboites Aguilar, L., D. Birrichaga Gardida y J.A. Garay Trejo (2010), "El manejo de las aguas mexicanas en el siglo xx", en B. Jiménez, M.L. Torregrosa y Armentia, y L. Aboites (eds.), El agua en México: Cauces y encauces, Ciudad de México, Academia Mexicana de Ciencias, pp. 21-50.

Alfaro, J. y M.P. Martín (2015), "Proceso y oportunidades de la transferencia del conocimiento desde la psicología comunitaria a las políticas públicas", Universitas Psychologica, 14(4), pp. 1347-1358.

Arreguín Cortés, F.I., M. López Pérez y H. Marengo Mogollón (2011), “Mexico’s Water Challenges for the $21^{\text {st }}$ Century", en U. Oswald (ed.), Water Resources in Mexico: Scarcity, Degradation, Stress, Conflicts, Management, and Policy, Berlín, Springer-Verlag, pp. 21-38.

Arreguín Cortés, F.I., P. Martínez Austria y V. Trueba López (2004), “El agua en México: Una visión institucional”, en B. Jiménez y L. Marín (eds.), El agua en México vista desde la academia, Ciudad de México, Academia Mexicana de Ciencias, pp. 251-270, disponible en: https://www.researchgate.net/publication/266218968_El_agua_en_Mexico_una_vision_institucional [fecha de consulta: 22 de octubre de 2019].

Arreguín Cortés, F.I., V. Alcocer Yamanaka, H. Marengo Mogollón, C. Cervantes Jaimes, P. Albornoz Góngora y M.G. Salinas Juárez (2010), "Los retos del agua”, en B. Jiménez, M.L. Torregrosa y Armentia, y L. Aboites (eds.), El agua en México: Cauces y encauces, Ciudad de México, Academia Mexicana de Ciencias, pp. 51-78.

Ávila García, P. (2006), "El valor social y cultural del agua”, en V. Vázquez, D. Soares, A. de la Rosa y A. Serrano (coords.), Gestión y cultura del agua, tomo II, Ciudad de México, Instituto Mexicano de Tecnología del Agua/Colegio de Postgraduados en Ciencias Agrícolas, pp. 233-248. 
Ávila García, P. (2008), "Vulnerabilidad socioambiental, seguridad hídrica y escenarios de crisis por el agua en México", Ciencias, 90, pp. 46-57.

Berkes, F., J. Colding y C. Folke (2002), Navigating Social-Ecological Systems: Building Resilience for Complexity and Change, Cambridge, Cambridge University Press, 393 pp.

Beutelspacher, N., D. Austreberta, E. Zapata Martelo y V. Ramírez Castel (2010), "Género y agua: Reflexiones sobre las estrategias internacionales para lograr la sustentabilidad con equidad", en B. Jiménez, M.L. Torregrosa y Armentia, y L. Aboites (eds.), El agua en México: Cauces y encauces, Ciudad de México, Academia Mexicana de Ciencias, pp. 383-410.

Brenner, L. y D. Vargas del Río (2010), "Gobernabilidad y gobernanza ambiental en México: La experiencia de la Reserva de la Biosfera Sian Ka’an”, Polis, 6(2), pp. 115-154, disponible en: http://www.scielo.org.mx/scielo.php?script=sci_arttext\&pid=S187023332010000200005\&lng=es\&tlng=es [fecha de consulta: 1 de octubre de 2019].

Bullen, E., S. Robb y J. Kenway (2004), “'Creative Destruction': Knowledge Economy Policy and the Future of the Arts and Humanities in the Academy", Journal of Education Policy, 19(1), pp. 3-22, Dor: 10.1080/0268093042000182609.

Capel, H. (2014), "Ciencia ciudadana, ética y política para viejos y nuevos problemas", Biblio 3W: Revista Bibliográfica de Geografía y Ciencias Sociales, 19(96), disponible en: http://www.ub.es/geocrit/b3w-1096.htm [fecha de consulta: 8 de junio de 2019].

Castillo, L. y D. Velázquez (2015), "Sistemas complejos adaptativos, sistemas socio-ecológicos y resiliencias", Quivera: Revista de Estudios Territoriales, 17(2), pp. 11-32, disponible en: https:/quivera.uaemex.mx/article/view/9811 [fecha de consulta: $28 \mathrm{de}$ noviembre de 2019].

Cotler, H. (2015), "Incidencia del enfoque de cuencas en las políticas públicas de México", en A. Burgos, G. Bocco y J. Sosa (coords.), Dimensiones sociales en el manejo de cuencas, Ciudad de México, Universidad Nacional Autónoma de México/Centro de Investigaciones en Geografía Ambiental, pp. 31-44.

DOF (1992), Ley de Aguas Nacionales, Diario Oficial de la Federación, disponible en: http:// www.ordenjuridico.gob.mx/leyes.php\# [fecha de consulta: 4 de noviembre de 2019].

Domínguez, J. (2011), “Agua y territorio: Políticas y normatividad”, presentado durante Tercer Coloquio: Ciudades en Cuencas Sustentables, Ciudad de México, El Colegio de México, 4-6 de octubre, disponible en: https://www.yumpu.com/es/document/ $\mathrm{read} / 14191202 /$ dra-judith-dominguez-serrano-atl-el-portal-del-agua-desde-mexico [fecha de consulta: 1 de noviembre de 2019].

Domínguez, J. (2019), La política del agua en México a través de sus instituciones, 1917-2017, Ciudad de México, El Colegio de México-Centro de Estudios Demográficos, Urbanos y Ambientales, $273 \mathrm{pp}$. 
Dourojeanni, A., A. Jouravlev y G. Chávez (2002), Gestión del agua a nivel de cuencas: Teoría y práctica, Serie Recursos Naturales e Infraestructura, 47, Santiago de Chile, CEPAL, disponible en: https://repositorio.cepal.org/bitstream/handle/11362/6407/ s028593.pdf?sequence $=1$ [fecha de consulta: 3 de octubre de 2019].

Galán, C., P. Balvanera y F. Castellarini (2012), Politicas públicas hacia la sustentabilidad: Integrando la visión ecosistémica, Ciudad de México, Conabio, disponible en: http:// www.iies.unam.mx/wp-content/uploads/2016/03/Libro-CONABIO_Politicas_Publicas.pdf [fecha de consulta: 18 de octubre de 2019].

Gutiérrez Rivas, R. (2008), "El derecho fundamental al agua en México: Un instrumento de protección para las personas y los ecosistemas", Cuestiones Constitucionales, 18, pp. 71-90, disponible en: http://www.scielo.org. $\mathrm{mx} /$ scielo.php?script=sci_arttext\&pid= S140591932008000100003\&lng=es\&tlng=es [fecha de consulta: 10 de octubre de 2019].

Haines-Young, R. y M. Potschin (2017), Common International Classification of Ecosystem Services (CICES) V5.1 and Guidance on the Application of the Revised Structure, Nottingham, Fabis Consulting, disponible en: https://seea.un.org/sites/seea.un.org/files/lg23_cices_ v5.1_final_revised_guidance_03-10-2017.pdf [fecha de consulta: 8 de junio de 2019].

Jones, B.F. (2011), “As Science Evolves, How Can Science Policy?”, Innovation Policy and the Economy, 11(1), pp. 103-131.

Juntti, M., D. Russel y J. Turnpenny (2009), "Evidence, Politics and Power in Public Policy for the Environment", Environmental Science \& Policy, 12(3), pp. 207-215, DoI: 10.1016/j.envsci.2008.12.007.

Leff, E. (1994), Ecología y capital: Racionalidad ambiental, democracia participativa y desarrollo sustentable, Ciudad de México, UNAM-IIs/Siglo XXI.

Lemos, M.C. y B.J. Morehouse (2005), "The Co-production of Science and Policy in Integrated Climate Assessments”, Global Environmental Change, 15(1), pp. 57-68, DoI: 10.1016/j.gloenvcha.2004.09.004.

López de Lara, D., S. Murillo Sandoval y V.M. López (2018), “Gobernanza ambiental: El Consejo Asesor (CA) del Parque Nacional Huatulco (PNH) como un instrumento de conocimiento transdisciplinario", Acta Universitaria, 28(4), pp. 56-73, Dor: https:// dx.doi.org/10.15174/au.2018.1628.

López Morales, C.A. (2017), "El estado del agua en México: Retos, oportunidades y perspectivas", en Christian Denzin, Federico Taboada y Raúl Pacheco-Vega (eds.), El agua en México: Actores, sectores y paradigmas para una transformación social-ecológica, Ciudad de México, Friedrich-Ebert-Stiftung, pp. 13-42.

Martín, B., E. Gómez, M. García y C. Montes (2014), "Trade-offs across Value-domains in Ecosystem Services Assessment”, Ecological Indicators, 37 (part A), pp. 220-228, DoI: https://doi.org/10.1016/j.ecolind.2013.03.003. 
Martínez Austria, P.F. (2013), "Los retos de la seguridad hídrica", Tecnología y Ciencias del Agua, IV(5), pp. 165-180, disponible en: https://www.redalyc.org/articulo.oa?id= 3535/353531985011 [fecha de consulta: 21 de septiembre de 2019].

Martínez Austria, P.F., C. Díaz y G. Moeller (2019), "Water Security in México: General Diagnosis and Main Challenges", Ingeniería del Agua, 23(2), pp. 107-121, Dor: https:// doi.org/10.4995/ia.2019.10502.

Martínez Austria, P.F. y C. Patiño-Gómez (2012), "Efectos del cambio climático en la disponibilidad de agua en México", Tecnología y Ciencias del Agua, III(1), pp. 5-20.

MEA (Millenium Ecosystem Assessment) (2005), Ecosystem and Human Well-being: A Framework for Assessment, Washington, D.C., Island Press, disponible en: https://www. millenniumassessment.org/en/Framework.html [fecha de consulta: 19 de octubre de 2019].

Mussetta, P. (2009), "Participación y gobernanza: El modelo de gobierno del agua en México", Espacios Públicos, 12(25), pp. 66-84, disponible en: http://www.redalyc.org/articulo.oa?id=67611350005 [fecha de consulta: 24 de octubre de 2019].

Nava, L.F. (2006), "Cuando la gestión del agua se vuelve problemática: El caso de México", Observatoire des Amériques, 6(38), pp. 1-10, disponible en: https://www.researchgate. net/publication/304791720_Cuando_la_gestion_del_agua_se_vuelve_problematica_ el_caso_de_Mexico [fecha de consulta: 21 de septiembre de 2019].

Nava, L.F. (2018), "La desafiante gestión integrada de los recursos hídricos en México: Elaboración de recomendaciones políticas”, en J.O. Rojas, A. Torres y O. González (eds.), Las ciencias en los estudios del agua: Viejos desafios sociales y nuevos retos, Guadalajara, Editorial Universitaria, pp. 26-42.

OCDE (Organización para la Cooperación y el Desarrollo Económicos) (2013), Hacer posible la reforma de la gestión del agua en México, París, OCDE, DoI: https://doi.org/ 10.1787/9789264188075-es.

Orach, K. y M. Schlüter (2016), "Uncovering the Political Dimension of Social-ecological Systems: Contributions from Policy Process Frameworks", Global Environmental Change, 40, pp. 13-25, Dor: https://doi.org/10.1016/j.gloenvcha.2016.06.002.

Ortiz Rendón, G. (1993), "Conceptos originales relevantes de la Ley de Aguas Nacionales", Ingeniería Hidráulica en México, 1, pp. 7-13, Jiutepec, Mor., Instituto Mexicano de Tecnología del Agua.

Ortiz Rendón, G. (2005), Evolución y perspectivas del marco jurídico del agua en México: Nuevos retos y oportunidades para la gestión integrada del recurso agua, Ciudad de México, UNAM, disponible en: https://archivos.juridicas.unam.mx/www/bjv/libros/6/2598/6. pdf [fecha de consulta: 6 de marzo de 2020].

Ostrom, E. (2009), "A General Framework for Analyzing Sustainability of Social-ecological Systems”, Science, 325(5939), pp. 419-422, DoI: https://doi.org/10.1126/science.1172133. 
Ouyang, W., A.K. Skidmore, A.G. Toxopeus y F. Hao (2010), "Long-term Vegetation Landscape Pattern with Non-point Source Nutrient Pollution in Upper Stream of Yellow River Basin", Journal of Hydrology, 389(3-4), pp. 373-380, Dor: https://doi.org/10.1016/j. jhydrol.2010.06.020.

Pohl, C. (2008), "From Science to Policy through Transdisciplinary Research", Environmental Sciences and Policy, 11, pp. 46-53, Dor: 10.1016/j.envsci.2007.06.001.

Ramírez Treviño, A., J.M. Sánchez Núńez y A. García Camacho (2003), "El desarrollo sustentable: Interpretación y análisis", Revista del Centro de Investigación de la Universidad la Salle, 6(21), pp. 55-55.

Reed, M.S. (2008), "Stakeholder participation for Environmental Management: A Literature Review”, Biological Conservation, 141(10), pp. 2417-2431, Dor: 10.1016/j.biocon.2008.07.014.

Rodríguez Romero, P.C. y A. Cubillos González (2012), "Los elementos para la valoración integral de los recursos naturales: Un puente entre la economía ambiental y la economía y la economía ecológica una revisión de bibliografía”, Gestión y Ambiente, 15(1), pp. 77-90, disponible en: https://revistas.unal.edu.co/index.php/gestion/rt/printerfriendly/30819/39305 [fecha de consulta: 21 de marzo de 2020].

Romero Pérez, J.E. (2007), "El agua como bien económico", Revista de Ciencias Jurídicas, 113, pp. 115-150.

Salinas-Castillo, W.E. y E.J. Treviño-Garza (2002), "Impacto de la deforestación en el microclima de la subcuenca río Corona, Tamaulipas, México", Investigaciones Geográficas, 47, pp. 59-76, disponible en: https://www.redalyc.org/articulo.oa?id=56904705 [fecha de consulta: 11 de marzo de 2020].

Schlüter, M., J. Haider, S. Lade, E. Lindkvist, R. Martin, K. Orach, N. Wijermans y C. Folke (2019), "Capturing Emergent Phenomena in Social-ecological Systems: An Analytical Framework”, Ecology and Society, 24(3), pp. 1-11, Dor: https://doi.org/10.5751/ ES-11012-240311.

Senabre, E., N. Ferran-Ferrer y J. Perelló (2018), "Diseño participativo de experimentos de ciencia ciudadana”, Comunicar, 26(54), pp. 29-38, DoI: https://doi.org/10.3916/C542018-03.

Sivapalan, M., H. Savenije y G. Bloschl (2012), “Sociohydrology: A New Science of People and Water”, Hydrological Processes, 26, pp. 1270-1276, disponible en: https://onlinelibrary.wiley.com/doi/abs/10.1002/hyp.8426 [fecha de consulta: 4 de septiembre de 2019].

Stubrin, L. y Y. Kababe (2014), "La interrelación entre la investigación científica y las políticas públicas en ciencia, tecnología e innovación en la Argentina”, Redes, 20(39), pp. 73-103. 
von Bertalanffy, L. (1968), General Systems Theory, Nueva York, George Brazilier.

Walters, C.J. (1986), Adaptive Management of Renewable Resources, Nueva York, McGraw-Hill. wHO (World Health Organization) (2005), Ecosystems and Human Well-being: Health Synthesis, disponible en: https://www.millenniumassessment.org/documents/document.357. aspx.pdf [fecha de consulta: 29 de marzo de 2020].

Wiek, A. y K. Larson (2012), "Water, People, and Sustainability: A Systems Framework for Analyzing and Assessing Water Governance Regimes", Water Resources Management, 26(11), pp. 3153-3171, disponible en: https://asu.pure.elsevier.com/en/publications/ water-people-and-sustainability-a-systems-framework-for-analyzing [fecha de consulta: 16 de septiembre de 2019].

Wilder, M. (2010), "Water Governance in Mexico: Political and Economic Apertures and a Shifting State-citizen Relationship", Ecology and Society, 15(2), disponible en: http:// www.ecologyandsociety.org/vol15/iss2/art22/ [fecha de consulta: 15 de octubre de 2019].

Wong, C., B. Jiang, A. Kinzig, K. Lee y Z. Ouyang (2014), "Linking Ecosystem Characteristics to Final Ecosystem Services for Public Policy”, Ecology Letters, 18(1), pp. 108-118, DOI: https://doi.org/10.1111/ele.12389.

Zhao, T., H. Xu, Y. He, C. Tai, H. Meng, F. Zeng y M. Xing (2009), “Agricultural Nonpoint Nitrogen Pollution Control Function of Different Vegetation Types in Riparian Wetlands: A Case Study in the Yellow River Wetland in China", Journal of Environmental Sciences, 21(7), pp. 933-939, Dor: https://doi.org/10.1016/S1001-0742(08)62364-5. 


\section{ANEXOS}

\section{Anexo 1. Principios enlistados en el artículo 14 Bis 5.}

Artículo 14 Bis 5 . Los principios que sustentan la política hídrica nacional son: I. El agua es un bien de dominio público federal, vital, vulnerable y finito, con valor social, económico y ambiental, cuya preservación en cantidad y calidad y sustentabilidad es tarea fundamental del Estado y la Sociedad, así como prioridad y asunto de seguridad nacional;

II. La gestión integrada de los recursos hídricos por cuenca hidrológica es la base de la política hídrica nacional;

III. La gestión de los recursos hídricos se llevará a cabo en forma descentralizada e integrada privilegiando la acción directa y las decisiones por parte de los actores locales y por cuenca hidrológica;

IV. Los estados, Distrito Federal, municipios, consejos de cuenca, organizaciones de usuarios y de la sociedad, organismos de cuenca y "la Comisión", son elementos básicos en la descentralización de la gestión de los recursos hídricos;

V. La atención de las necesidades de agua provenientes de la sociedad para su bienestar, de la economía para su desarrollo y del ambiente para su equilibrio y conservación; particularmente, la atención especial de dichas necesidades para la población marginada y menos favorecida económicamente;

VI. Los usos del agua en las cuencas hidrológicas, incluyendo los acuíferos y los trasvases entre cuencas, deben ser regulados por el Estado;

VII. El Ejecutivo Federal se asegurará que las concesiones y asignaciones de agua estén fundamentadas en la disponibilidad efectiva del recurso en las regiones hidrológicas y cuencas hidrológicas que correspondan, e instrumentará mecanismos para mantener o reestablecer el equilibrio hidrológico en las cuencas hidrológicas del país y el de los ecosistemas vitales para el agua;

VIII. El Ejecutivo Federal fomentará la solidaridad en materia de agua entre los estados, Distrito Federal, municipios, entre usuarios y entre organizaciones de la sociedad, en las distintas porciones de las cuencas, subcuencas y microcuencas, con el concurso de consejos y organismos de cuenca;

IX. La conservación, preservación, protección y restauración del agua en cantidad y calidad es asunto de seguridad nacional, por tanto, debe evitarse el aprovechamiento no sustentable y los efectos ecológicos adversos;

$\mathrm{X}$. La gestión integrada de los recursos hídricos por cuenca hidrológica, se sustenta en el uso múltiple y sustentable de las aguas y la interrelación que existe entre los recursos hídricos con el aire, el suelo, flora, fauna, otros recursos natu- 
rales, la biodiversidad y los ecosistemas que son vitales para el agua;

XI. El agua proporciona servicios ambientales que deben reconocerse, cuantificarse y pagarse, en términos de Ley;

XII. El aprovechamiento del agua debe realizarse con eficiencia y debe promoverse su reúso y recirculación;

XIII. El Ejecutivo Federal promoverá que los estados, el Distrito Federal y los municipios a través de sus órganos competentes y arreglos institucionales que estos determinen, se hagan responsables de la gestión de las aguas nacionales en cantidad y calidad que tengan asignadas, concesionadas o bajo su administración y custodia y de la prestación de los servicios hidráulicos; el Ejecutivo Federal brindará facilidades y apoyo para la creación o mejoramiento de órganos estatales competentes que posibiliten la instrumentación de lo dispuesto en la presente fracción;

XIV. En particular, el Ejecutivo Federal establecerá las medidas necesarias para mantener una adecuada calidad del agua para consumo humano y con ello incidir en la salud pública; para el mejor cumplimiento esta política, se coordinará y solicitará los apoyos necesarios a los estados, Distrito Federal y municipios;

$\mathrm{XV}$. La gestión del agua debe generar recursos económicos y financieros necesarios para realizar sus tareas inherentes, bajo el principio de que "el agua paga el agua", conforme a las Leyes en la materia;

XVI. Los usuarios del agua deben pagar por su explotación, uso o aprovechamiento bajo el principio de "usuario-pagador" de acuerdo con lo dispuesto en la Ley Federal de Derechos;

XVII. Las personas físicas o morales que contaminen los recursos hídricos son responsables de restaurar su calidad, y se aplicará el principio de que "quien contamina, paga”, conforme a las Leyes en la materia;

XVIII. Las personas físicas o morales que hagan un uso eficiente y limpio del agua se harán acreedores a incentivos económicos, incluyendo los de carácter fiscal, que establezcan las Leyes en la materia;

XIX. El derecho de la sociedad y sus instituciones, en los tres órdenes de gobierno, a la información oportuna, plena y fidedigna acerca de la ocurrencia, disponibilidad y necesidades de agua, superficial y subterránea, en cantidad y calidad, en el espacio geográfico y en el tiempo, así como a la relacionada. 
ANEXO 2. Nube de palabras de los principios que rigen la LAN

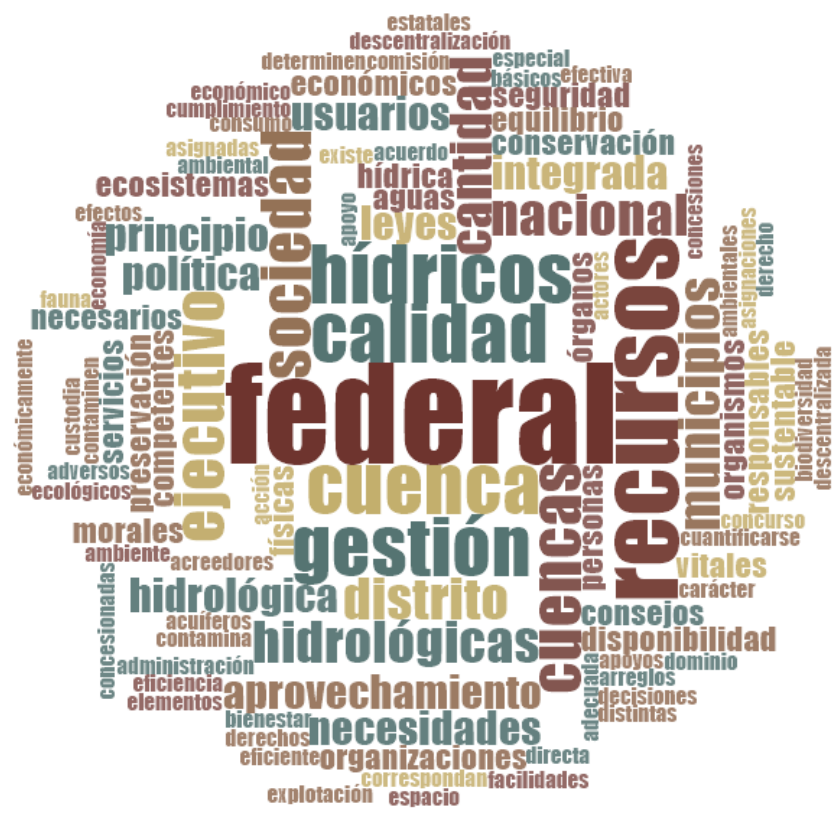

Fuente: Elaboración propia con base en la LAN. 


\section{ANEXO 3. Palabras clave para la identificación de los componentes y elementos del sistema sociohidrológico}

\begin{tabular}{|c|c|c|c|}
\hline Elemento & Palabra clave & $F$ & Ubicación \\
\hline Perspectiva sistémica & $\begin{array}{l}\text { Gestión integrada de los } \\
\text { recursos hídricos }\end{array}$ & 25 & $\begin{array}{l}\text { 3, 7, } 7 \text { Bis, } 9,12 \text { Bis, } 12 \text { Bis } 1,12 \text { Bis } 5,12 \text { Bis } \\
6,12 \text { Bis 1,13 Bis 3,14 Bis,14 Bis 1, } 14 \text { Bis 3, } \\
14 \text { Bis 5, 15, } 111 \text { Bis }\end{array}$ \\
\hline $\begin{array}{l}\text { Enfoque en actores } \\
\text { sociales }\end{array}$ & Actores & 1 & 14 Bis 5 \\
\hline $\begin{array}{l}\text { Discurso transparente } \\
\text { sobre metas y valores }\end{array}$ & $\mathrm{N} / \mathrm{A}$ & N/A & 14 Bis 5 \\
\hline \multirow{2}{*}{$\begin{array}{l}\text { Perspectiva } \\
\text { comprensiva sobre } \\
\text { sustentabilidad del } \\
\text { agua }\end{array}$} & Sustentable & 15 & 3, 6, 13 Bis 3,14 Bis, 14 Bis 3, 14 Bis 5 \\
\hline & Sustentabilidad & 13 & 3, 6, 7 Bis, 13 Bis 4, 14 Bis 5, 15, 39 Bis \\
\hline \multirow[t]{8}{*}{$\begin{array}{l}\text { Concepto de } \\
\text { delimitación }\end{array}$} & Cuenca & 265 & $\begin{array}{l}3,5,7,7 \text { Bis, } 9,11,12,12 \text { Bis } 1,12 \text { Bis } 2,12 \text { Bis } \\
3,12 \text { Bis } 4,12 \text { Bis } 5,12 \text { Bis } 6,13,13 \text { Bis, } 13 \text { Bis } \\
1,13 \text { Bis } 2,13 \text { Bis } 3,14,14 \text { Bis, } 14 \text { Bis 4, } 14 \text { Bis } \\
5,14 \text { Bis } 6,15,15 \text { Bis, } 19 \text { Bis, 20, 21, 22, 23, } \\
30,33,34,38,40,42,44,52 \text { Bis, 59, 61, 65, } \\
66,67,68,69,69 \text { Bis, 72, 73, 74, 75, 76, 82, } \\
83,84,84 \text { Bis, } 84 \text { Bis } 1,84 \text { Bis 2, 86, 86 Bis, } 86 \\
\text { Bis } 1,96,96 \text { Bis 1, 112, } 113 \text { Bis } 1,119,124\end{array}$ \\
\hline & Cuencas & 51 & $\begin{array}{l}3,6,7,7 \text { Bis, } 9,12 \text { Bis, } 12 \text { Bis } 1,12 \text { Bis } 4,12 \text { Bis } \\
6,13,13 \text { Bis } 1,13 \text { Bis } 3,14 \text { Bis } 5,15,32,33 \text {, } \\
38,39 \text { Bis, } 77,86,96 \text { Bis } 2\end{array}$ \\
\hline & Cuenca hidrológica & 44 & $\begin{array}{l}\text { 3, 5, 6, } 7 \text { Bis, } 12 \text { Bis } 1,12 \text { Bis } 3,12 \text { Bis } 6,13 \text { Bis, } \\
13 \text { Bis } 1,13 \text { Bis } 2,14 \text { Bis } 5,14 \text { Bis } 6,21,22,23, \\
29,33,34,38,52 \text { Bis, } 86,95\end{array}$ \\
\hline & Cuencas hidrológicas & 33 & $\begin{array}{l}\text { 3, 6, 7, 9, } 12 \text { Bis, } 12 \text { Bis } 1,12 \text { Bis 4, } 12 \text { Bis } 6,13, \\
13 \text { Bis 1, } 13 \text { Bis } 3,14 \text { Bis } 5,15,38,86\end{array}$ \\
\hline & Región hidrológica & 16 & $\begin{array}{l}3,5,7,12 \text { Bis } 6,13 \text { Bis } 1,13 \text { Bis } 2,14 \text { Bis } 5,14 \\
\text { Bis } 6,21,22,23,33,34,86,96 \text { Bis } 2\end{array}$ \\
\hline & Regiones hidrológicas & 18 & $\begin{array}{l}3,6,7,9,12 \text { Bis, } 12 \text { Bis } 1,12 \text { Bis } 5,14 \text { Bis } 5,15, \\
32,38,84 \text { Bis }\end{array}$ \\
\hline & $\begin{array}{l}\text { Región hidrológico } \\
\text { administrativa }\end{array}$ & 5 & 3,12 Bis 2,30 \\
\hline & $\begin{array}{l}\text { Regiones hidrológico } \\
\text { administrativas }\end{array}$ & 4 & 9, 12 Bis, 12 Bis 1, 30 \\
\hline
\end{tabular}


ANEXO 3. Palabras clave para la identificación de los componentes y elementos del sistema sociohidrológico (continuación)

\begin{tabular}{|c|c|c|c|}
\hline Elemento & Palabra clave & $F$ & Ubicación \\
\hline \multicolumn{4}{|c|}{ Dominios de actividad } \\
\hline \multirow[t]{16}{*}{ Suministros } & Acuífero & 14 & $\begin{array}{l}\text { 3, 6, 7, } 7 \text { Bis, } 12 \text { Bis } 6,13 \text { Bis } 1,13 \text { Bis } 2,13 \text { Bis } \\
\text { 3, 15, } 18,21,22,23,29 \text { Bis 3, } 29 \text { Bis 4, 31, 33, } \\
\text { 39 Bis, 42, 47, 81, 86, 88, 91, 96, } 119\end{array}$ \\
\hline & Acuíferos & 44 & $\begin{array}{l}3,6,7,7 \text { Bis, } 13 \text { Bis } 1,13 \text { Bis } 2,13 \text { Bis } 3,14 \text { Bis } \\
5,15,18,29 \text { Bis } 3,32,33,39,39 \text { Bis, } 42,47, \\
81,86,88,91\end{array}$ \\
\hline & Aguas claras o aguas de primer uso & 1 & 3 \\
\hline & Aguas de subsuelo & 22 & $\begin{array}{l}3,13 \text { Bis } 1,13 \text { Bis } 3,15,18,19,23,29,29 \text { Bis } \\
4,35,42,81,119,32\end{array}$ \\
\hline & Aguas marinas & 6 & $3,17,29$ Bis $4,88,119$ \\
\hline & Estero & 3 & 3,114 \\
\hline & Esteros & 4 & 113,119 \\
\hline & Río & 3 & 3 \\
\hline & Ríos & 3 & 3,119 \\
\hline & Lago & 3 & $3,78,114$ \\
\hline & Lagos & 5 & $113,117,119$ \\
\hline & Laguna & 4 & $3,78,114$ \\
\hline & Lagunas & 5 & $113,117,119$ \\
\hline & $\begin{array}{l}\text { Humedales (Pantanos, ciénagas, } \\
\text { marismas) }\end{array}$ & 7 & 3,86 Bis 1 \\
\hline & Ecosistema & 5 & $3,38,40,86$ Bis 1,96 \\
\hline & Ecosistemas & 38 & $\begin{array}{l}3,6,7,9,13 \text { Bis } 3,13 \text { Bis } 4,14 \text { Bis } 4,14 \text { Bis } 5, \\
15,29,29 \text { Bis } 4,29 \text { Bis } 5,29 \text { Bis } 6,40,41,84 \\
\text { Bis } 2,85,86 \text { Bis } 1,92,94,96 \text { Bis, } 100,113 \text { Bis, } \\
114,118 \text { Bis } 2\end{array}$ \\
\hline Distribuidores & $\begin{array}{l}\text { Sistema de agua potabley } \\
\text { alcantarillado }\end{array}$ & 1 & 3 \\
\hline \multirow[t]{4}{*}{ Usos } & Uso agrícola & 5 & $3,21,49$ \\
\hline & Uso ambiental & 4 & $3,15,29$ Bis 5 \\
\hline & Uso consuntivo & 4 & 3,25 \\
\hline & Uso doméstico & 13 & $\begin{array}{l}3,7,9,13 \text { Bis } 3,13 \text { Bis } 3,13 \text { Bis } 4,13 \text { Bis } 5,17 \\
22,41,44,88 \text { Bis } 1,91 \text { Bis }\end{array}$ \\
\hline
\end{tabular}




\section{ANEXO 3. Palabras clave para la identificación de los componentes y elementos del sistema sociohidrológico (co-ntinuación)}

\begin{tabular}{|c|c|c|c|}
\hline Elemento & Palabra clave & $F$ & Ubicación \\
\hline \multirow[t]{5}{*}{ Usos } & Uso en acuacultura & 1 & 3 \\
\hline & Uso industrial & 1 & 3 \\
\hline & Uso pecuario & 1 & 3 \\
\hline & Uso público urbano & 7 & 3,14 Bis $5,22,41,44$ \\
\hline & $\begin{array}{l}\text { Uso en la generación de energía } \\
\text { eléctrica }\end{array}$ & 1 & 78 \\
\hline \multirow[t]{4}{*}{ Salidas } & Agua residual & 4 & $3,22,88$ Bis \\
\hline & Aguas residuales & 89 & $\begin{array}{l}\text { 3, 7, 9, } 12 \text { Bis } 6,13 \text { Bis 3, 16, 21, } 21 \text { Bis, 22, 25, } \\
29 \text { Bis, } 29 \text { Bis 2, } 29 \text { Bis 4, 30, 44, 45, 47, 47 Bis, } \\
84 \text { Bis, } 86,86 \text { Bis 2, 88, 88 Bis, 88 Bis1, 89, 90, } \\
91,91 \text { Bis, } 91 \text { Bis 1, 92, 93, } 93 \text { Bis, } 94,94 \text { Bis, } \\
95,96 \text { Bis 1, } 112,118 \text { Bis 2, } 122\end{array}$ \\
\hline & Cuerpos receptores & 29 & $\begin{array}{l}\text { 3, 16, } 21 \text { Bis, } 22,29 \text { Bis, } 29 \text { Bis 4, 44, 45, } 81 \\
86 \text { Bis } 2,88,88 \text { Bis, } 81 \text { Bis 1, } 91 \text { Bis 1, } 92,93 \\
\text { Bis, } 112,119\end{array}$ \\
\hline & Cuerpo receptor & 8 & 3, 44, $91 \mathrm{Bis,} 96$ Bis 1 \\
\hline \multirow[t]{6}{*}{ Transversales } & Asignación & 66 & $\begin{array}{l}3,9,12,12 \text { Bis } 2,12 \text { Bis } 6,13 \text { Bis } 1,20,21,22, \\
23,24,25,29,29 \text { Bis } 2,29 \text { Bis } 3,29 \text { Bis } 4,29 \\
\text { Bis } 5,30,35,42,44,90,93,119,122\end{array}$ \\
\hline & Asignaciones & 17 & $\begin{array}{l}\text { 3, } 14 \text { Bis } 5,14 \text { Bis } 6,20,22,24,28,30,42,44, \\
94 \text { Bis. }\end{array}$ \\
\hline & Concesión & 135 & $\begin{array}{l}2,3,9,12,12 \text { Bis } 2,12 \text { Bis } 6,13 \text { Bis } 1,15,17, \\
20,21,22,23,23 \text { Bis, } 24,25,29,29 \text { Bis } 2,29 \\
\text { Bis } 3,29 \text { Bis } 4,29 \text { Bis } 5,30,33,34,35,36,42, \\
48,50,56,57,58,59,60,66,78,80,81,82, \\
90,93,102,104,105,106,107,113 \text { Bis, } 118 \\
\text { Bis, } 119,122\end{array}$ \\
\hline & Concesiones & 43 & $\begin{array}{l}\text { 3, 6, 9, } 12 \text { Bis } 6,14 \text { Bis } 5,14 \text { Bis } 6,16,20,22 \\
24,28,29 \text { Bis } 4,30,42,48,56 \text { Bis, } 81,82,94 \\
\text { Bis, } 102,103,105,113 \text { Bis, } 118,118 \text { Bis }\end{array}$ \\
\hline & Programa Nacional Hídrico & 7 & $3,6,9,12$ Bis, 14 Bis $3,15,29$ Bis 5 \\
\hline & Programa Hídrico de la cuenca & 4 & 3, 13 Bis $3,15,52$ Bis \\
\hline
\end{tabular}

Fuente: Elaboración propia con base en la LAN. Leyenda: F: frecuencia. En azul se indican las palabras en plural. En la búsqueda de información se consideraron las frecuencias plurales y singulares por separado bajo el supuesto de que esta diferenciación también podría brindar indicios sobre las implicaciones de los conceptos marcados. 
Yair Asael Alpuche Álvarez, de nacionalidad mexicana, es maestro en Ciencias en Recursos Naturales y Desarrollo Rural por El Colegio de la Frontera Sur (Ecosur). Sus líneas de investigación son: servicios ecosistémicos, sistemas socio-ecológicos, ciencias del paisaje, impulsores políticos de cambios.

Luzma Fabiola Nava, de nacionalidad mexicana, es catedrática-Conacyt en el Centro del Cambio Global y la Sustentabilidad, A.C., e investigadora invitada en el International Institute for Applied Systems Analysis (IIASA). Doctora en Estudios Internacionales por la Universidad Laval (Quebec, Canadá) y maestra en Ciencia Política por la Universidad de Quebec en Montreal (Montreal, Canadá). Sus líneas de investigación son: gestión y gobernanza de los recursos hídricos, geopolítica y sustentabilidad, participación de los grupos interesados.

Maritza Alejandra Carpio Candelero, de nacionalidad mexicana, es licenciada en Gestión Ambiental por la Universidad Juárez Autónoma de Tabasco (UJAT) en la División Académica de Ciencias Biológicas (DACBiol). Sus intereses de investigación son: organizaciones sociales, servicios ecosistémicos, gestión de recursos naturales, recursos hídricos y economía ambiental, y de los recursos naturales.

Diana Isabel Contreras Chablé, de nacionalidad mexicana, es licenciada en Gestión Ambiental por la Universidad Juárez Autónoma de Tabasco (UJAT) en la División Académica de Ciencias Biológicas (DACBiol). Sus intereses de investigación son: servicios ecosistémicos hidrológicos, políticas públicas, historia ambiental. 